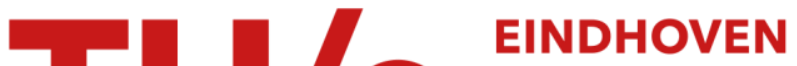

\section{Energy integration and interaction between buildings and vehicles: a state-of-the-art review}

Citation for published version (APA):

Zhou, Y., Cao, S., Hensen, J., \& Lund, P. D. (2019). Energy integration and interaction between buildings and vehicles: a state-of-the-art review. Renewable and Sustainable Energy Reviews, 114, [109337].

https://doi.org/10.1016/j.rser.2019.109337

\section{Document license:}

TAVERNE

DOI:

10.1016/j.rser.2019.109337

Document status and date:

Published: 01/10/2019

\section{Document Version:}

Publisher's PDF, also known as Version of Record (includes final page, issue and volume numbers)

\section{Please check the document version of this publication:}

- A submitted manuscript is the version of the article upon submission and before peer-review. There can be important differences between the submitted version and the official published version of record. People interested in the research are advised to contact the author for the final version of the publication, or visit the $\mathrm{DOI}$ to the publisher's website.

- The final author version and the galley proof are versions of the publication after peer review.

- The final published version features the final layout of the paper including the volume, issue and page numbers.

Link to publication

\section{General rights}

Copyright and moral rights for the publications made accessible in the public portal are retained by the authors and/or other copyright owners and it is a condition of accessing publications that users recognise and abide by the legal requirements associated with these rights.

- Users may download and print one copy of any publication from the public portal for the purpose of private study or research.

- You may not further distribute the material or use it for any profit-making activity or commercial gain

- You may freely distribute the URL identifying the publication in the public portal.

If the publication is distributed under the terms of Article $25 \mathrm{fa}$ of the Dutch Copyright Act, indicated by the "Taverne" license above, please follow below link for the End User Agreement:

www.tue.nl/taverne

Take down policy

If you believe that this document breaches copyright please contact us at:

openaccess@tue.nl

providing details and we will investigate your claim. 


\title{
Energy integration and interaction between buildings and vehicles: A state- of-the-art review
}

\author{
Yuekuan Zhou $^{\mathrm{a}}$, Sunliang Cao ${ }^{\mathrm{a}, *}$, Jan L.M. Hensen ${ }^{\mathrm{b}}$, Peter D. Lund ${ }^{\mathrm{c}}$ \\ ${ }^{a}$ Renewable Energy Research Group (RERG), Department of Building Services Engineering, Faculty of Construction and Environment, The Hong Kong Polytechnic \\ University, Kowloon, Hong Kong \\ ${ }^{\mathrm{b}}$ Department of the Built Environment, Eindhoven University of Technology (TU/e), the Netherlands \\ ${ }^{\mathrm{c}}$ Department of Applied Physics, School of Science, Aalto University, P.O.Box 15100, FI-00076, Aalto, Espoo, Finland
}

A R T I C L E IN F O

\section{Keywords:}

Building-vehicle integration

Building-to-Vehicle

Vehicle-to-Building

Renewable energy

Hybrid energy systems

\begin{abstract}
A B S T R A C T
Clean power production, buildings, and transportation are key areas for climate change mitigation. Their tighter integration decreases not only the emissions, but also the energy consumption of buildings and transportation. Energy integration and interactions between buildings and vehicles are dependent on the type of building, vehicle, and renewable energy system, as well as the local climatic conditions. The current academic literature does not provide a systematic analysis of this topic. In the study, different energy management systems and advanced energy control strategies have been formulated to study such interactions both from a building and a vehicle perspective. Furthermore, technical solutions have been systematically reviewed in terms of the enhancement of energy interaction capabilities, in particular from the standpoint of renewable energy systems, energy/fuel charging facilities, and control strategies. Assessment criteria employed in the review of solutions include grid interaction, annual operational cost, annual net $\mathrm{CO}_{2}$ emissions, and annual matching capability. The literature review identifies several technical challenges that need further consideration such as capacity expansion and power fluctuation of the electric grid, low efficiency of heat recovered from electricity generation, and depreciation of vehicles. The future outlook and potential for the energy interaction networks between buildings and vehicles have also been presented.
\end{abstract}

\section{Introduction}

The dependence on fossil fuels has resulted in a global environmental crisis, which jeopardises the existence of both modern society and natural ecosystems. For example, in Hong Kong, buildings accounted for $64 \%$ of the total energy consumption and transportation accounted for $31 \%$ [1]. From the perspective of end-use energy consumption, the energy consumption share of private vehicles increased from $18 \%$ to $24 \%$ from 2003 to 2013 due to the increased share of private vehicles in the market. At present, the renewable energy utilisation and energy efficiency improvement for both domestic usage and transportation have attracted an increasing interest all over the world. From the perspective of transportation, in comparison with traditional fuel-based vehicles, vehicles supported by the new energy sources, such as clean electricity, hydrogen, and biofuels, have been regarded as a promising solution to environmental problems [2]. Moreover, from the perspective of energy consumption, the transition from traditional fuelbased vehicles to renewable-supported vehicles will decrease the dependence on fossil fuels, mitigate the energy crisis, and reduce environmental pollution. In addition, compared to the traditional fossil fuels, renewable energy sources are more diversified, such as wind energy, solar energy, geothermal energy, biofuels, and so on.

With the rapid development of the vehicle technology, energy integrations and interactions between buildings and vehicles have drawn widespread attention among researchers, engineers, and manufacturers. A systematic overview of the energy integrations and interactions between buildings and vehicle is highly required to present the current situation and the challenges. The investigated vehicles include electric vehicles (EVs), hydrogen vehicles (HVs), and biofuel-based vehicles. The shared energy forms are diverse, including electrical energy, thermal energy, and fuel energy. Recently, for battery-based EV integrated building systems, researchers have focused on multi-objective investigation and optimisation, including energy consumption, greenhouse gas (GHG) emission, annual matching capability, and annual operational cost. In the academic world, the research objectives and methodologies concerning battery-based EV integrated building

\footnotetext{
* Corresponding author. .

E-mail addresses: sunliang.cao@polyu.edu.hk, caosunliang@msn.com (S. Cao).
} 


\begin{tabular}{|c|c|c|c|}
\hline $\mathrm{ABS}$ & absorption chiller & $\begin{array}{l}\mathrm{H}_{2} \\
\text { HEVs }\end{array}$ & $\begin{array}{l}\text { nyarogen } \\
\text { hybrid electric vehicles }\end{array}$ \\
\hline $\mathrm{B} 2 \mathrm{~V}$ & building-to-vehicle & ICEs & internal combustion engines \\
\hline $\mathrm{CO}_{2}$ & carbon dioxide & NPV & net present value \\
\hline CEF & equivalent carbon dioxide emission factor & NZEV & net zero energy/emission vehicle \\
\hline DSM & demand-side management & PHEV & plug-in hybrid electric vehicle \\
\hline DEMS & district energy management system & $\mathrm{PV} / \mathrm{T}$ & photovoltaic/thermal \\
\hline DHW & domestic hot water & PV & photovoltaic \\
\hline EMS & energy management system & RE-HW & excessive renewable-hot water \\
\hline EVSE & electric vehicle support equipment & SOFCs & solid oxide fuel cells \\
\hline EVs & electric vehicles & $\mathrm{TE}$ & thermal-electrical \\
\hline G2V & grid-to-vehicle & ZEB & zero energy building \\
\hline G2B & grid-to-building & & \\
\hline
\end{tabular}

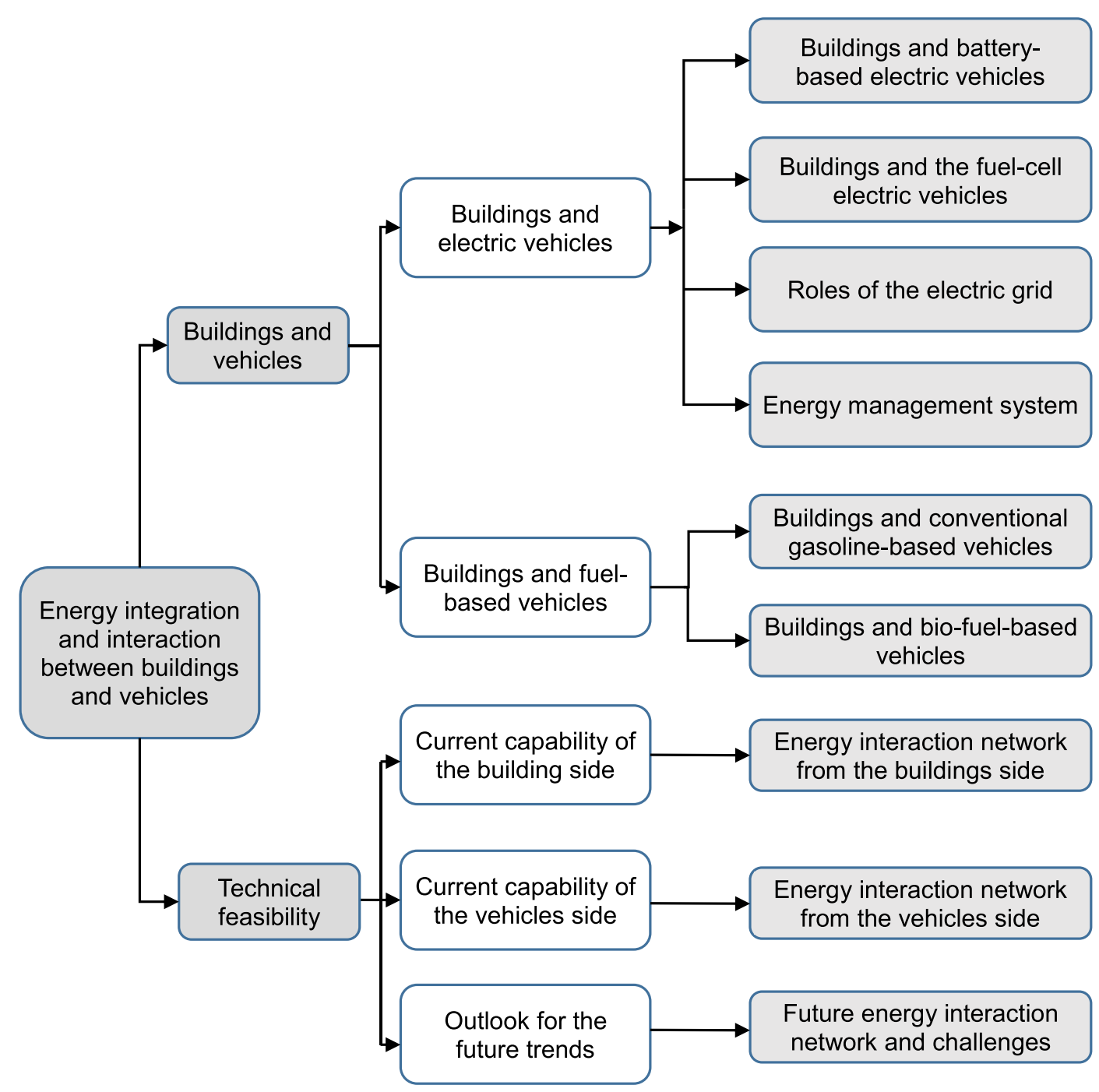

Fig. 1. Outlines of the energy integration and interaction between buildings and vehicles. 


\section{Energy integration and interaction between buildings and EVs}

\subsection{Buildings and battery-based EVs}

By implementing a unit for controlling the bidirectional power flow, the vehicle-to-building (V2B)/building-to-vehicle (B2V) interaction can be realised for reducing the reliance on the electric grid for both domestic usage and transportation. The concept of the V2B interaction is shown in Fig. 2. The primary objective is to flexibly adjust the operation of both the EV battery and the HVAC system in a building supported by renewable systems to satisfy the needs of the building occupants and the electric grid. From the available literature, several researchers have concentrated on the enhancement of energy sharing and renewable energy penetration by integrating battery-based EVs with buildings $[3,5,6]$.

In general, by integrating EVs with buildings, several anticipated objectives can be realised, which are briefly summarised as follows:

1) cutting energy consumption of buildings and transportation with an increased share for the renewable system;

2) reducing the import/export pressure on the electric grid;

3) shifting peak loads to sub-peak or off-peak periods and reducing the annual operational cost via the schematic operation of smart grids, smart vehicles, and smart buildings;

4) providing flexible energy for domestic usage and transportation with smart EV charging strategies and flexible demand-side management (DSM).

In other words, all above-mentioned objectives can be briefly summarised as the grid interaction, annual matching capability, annual net equivalent $\mathrm{CO}_{2}$ emission, and annual net operational cost. Table 2 summarises the holistic view of the energy sharing and interaction between buildings and battery-based EVs. Readers are suggested to check the listed references for different research methodologies and underlying mechanisms regarding different energy interaction networks. The challenges for the buildings and vehicles interaction network include the stochastic characteristic of the driving schedule of the electric vehicle [3], the accurate sizing approach of the renewable capacity with respect to different levels of the EV integration [6], and the impact of the building categories on the energy interactions considering both the occupants' and drivers' behaviours [5].

\subsection{Buildings and FCEVs}

The energy interaction network between HVs and buildings has attracted increasing interest recently, especially due to the availability of fourth-generation technologies such as the $\mathrm{H}_{2}$ storage tank with a maximum pressure of 700 bars $[8,9]$ and fuel-cell technologies for the oxidation process of $\mathrm{H}_{2}[10,11]$. Several HVs from different manufacturers have become commercialised recently, such as the Toyota Fuel Cell Hydrogen Vehicle-Advanced [64], the Toyota Mirai [65], the Hyundai Tucson Fuel Cell HV [66], and the Honda Clarity [67]. According to the results in Ref. [68], the annual imported electricity from the electric grid is reduced by $71 \%$ when FCEVs are integrated into the vehicle-to-grid (V2G) system. The underlying mechanism of the energy interaction network between buildings and HVs is that the $\mathrm{H}_{2}$ storage tank is discharged to activate the fuel cell in order to generate power for the building applications, and the source of the $\mathrm{H}_{2}$ can be from either a renewable-driven electrolyser or $\mathrm{a}_{2}$ station. The energy integration between FCEVs and buildings is highly dependent on the efficiency of both the electrolyser and the fuel cell, renewable capacities, the dynamic building load, the stochastic driving schedule, and so on. This section first reviews the energy interaction between the fuel-cell EV and buildings with diversified energy conversion, advanced energy storage, and electric grid interactions. Afterwards, assessment criteria are presented and technical solutions are proposed to improve the technical effectiveness of the energy interaction network between HVs and buildings.

As shown in Fig. 3(a), the EMS for the interaction between hydrogen FCEVs and buildings comprises the on-site renewable system, the integrated $\mathrm{H}_{2}$ system of hydrogen FCEVs, and the hybrid thermal storage. The hydrogen in the FCEVs can be either bio-hydrogen or electricitydriven hydrogen. The bio-hydrogen can be generated from food waste [69] and fermentation effluents [70]. Readers are suggested to refer to our previous studies [40] for more detailed information on the integrated $\mathrm{H}_{2}$ system of electricity-driven hydrogen FCEVs. The assessment criteria for the energy interaction network between buildings and HVs can be summarised from perspectives of energy, environment, and economy as listed in Table 3.

Cao et al. [40] investigated the technical feasibility of HV integration with a residential zero energy building (ZEB) in Finland. Their results showed that the proposed hybrid system can enhance the annual matching capability, realise zero-emission HVs, and reduce the cruise anxiety of $\mathrm{HV}$ drivers with convenient accessibility to the $\mathrm{H}_{2}$ refuelling station. In addition, Cao [12] also compared the difference between using HVs, using electric vehicles (EVs), and not using any vehicles from the perspectives of the energy and environment. According to the results, compared to the $\mathrm{EV}$, the $\mathrm{HV}$ was more demanding in regard to the annual net zero energy/emission balance due to the lower efficiency of the HV system. Moreover, technical solutions, such as relieving the condition for discharging the vehicle storage and adopting an excessive renewable-hot water (RE-HW) recharging strategy, are effective in improving the annual matching index. Cao et al. [21] also investigated the impact of the ground source heat pump (GSHP) and different configurations of hybrid renewable systems on the performance of the energy interaction network. Their results indicated that the GSHP is beneficial for realising net zero energy balance and improving the overall matching capability. The optimal configuration of the hybrid renewable system includes a PV generation share of $20 \%$ in Helsinki and $60 \%$ in Freiburg, respectively. Robledo et al. [13] investigated the effect of the FCEV integration on the energy interaction between the net ZEB and the microgrid. The investigated system included 10 all-electric dwellings and 5 different FCEVs. Their results showed that the annual imported electricity from the grid can be reduced by $71 \%$ with the FCEV integration. Moreover, the FCEV integration is beneficial for realising a ZEB. From the economic standpoint, Cao et al. [14] conducted a parametric study on the ZEB integrated with a zero-emission $\mathrm{HV}$. Their results indicated that the on-site $\mathrm{H}_{2}$ system will not show any

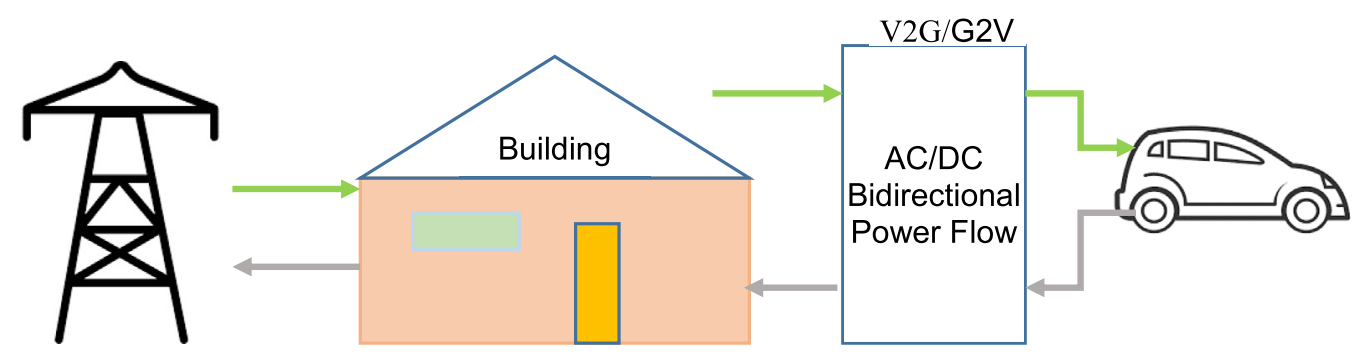

Fig. 2. Vehicle-to-building (V2B) concept $[24,25]$. 
Table 2

A holistic view of the energy integration and interaction between buildings and battery-based electric vehicles (EVs).

\begin{tabular}{|c|c|c|c|}
\hline Renewable energy & \multicolumn{3}{|c|}{ Solar photovoltaics [23]; Grid-tied and off-grid connected solar panels $[28,42]$} \\
\hline Building type & \multicolumn{3}{|c|}{ Retail building [23]; Building cluster [5]; University building [24]; Residential community [26]; Commercial and industrial buildings [31] } \\
\hline Interaction mode & \multicolumn{3}{|c|}{ B2V and V2B [23]; V2G,V2B and B2V [5]; V2B and B2V; Multiple B2V charging and V2B discharging modes [26]; V2B [49] } \\
\hline EMS & \multicolumn{3}{|c|}{ EV's fast charging and demand side management [23]; The EV charging schedule optimisation [29]; An efficient V2B/B2V network [5] } \\
\hline \multirow[t]{6}{*}{ Research objectives } & Energy & $\begin{array}{l}\text { Building demand/grid } \\
\text { interaction }\end{array}$ & $\begin{array}{l}\text { Building electric load [23,24]; Building energy efficiency and customer comfort [4]; Grid interaction } \\
\text { index [57]; Capacity factor [59] }\end{array}$ \\
\hline & & Matching & $\begin{array}{l}\text { Solar fraction }[27,41,52,55-60] \text {; Load matching index }[27,57] \text {; On-site energy fraction and the on- } \\
\text { site energy matching }[52,62,63]\end{array}$ \\
\hline & & Building energy flexibil & \\
\hline & & Smart readiness of buil & rgy system $[20,61]$ \\
\hline & Emission & Net equivalent $\mathrm{CO}_{2}$ em & $8,30,39,42]$ \\
\hline & Net operational cost & $\begin{array}{l}\text { Time-of-use prices of th } \\
\text { occupants' behaviors }\end{array}$ & city [54]; Emission cost for the electricity production [54]; Economic savings [26]; Drivers' and the \\
\hline
\end{tabular}

benefits in regard to both the equivalent $\mathrm{CO}_{2}$ emission and the relative NPV unless the cost of the electrolyser is lowered to $2000 \mathrm{EUR} / \mathrm{kW}$.

Due to the limited space for installing a renewable system in highrise buildings, several studies focused on installing a renewable system in vehicles, such as vehicle-integrated photovoltaics, a vehicle-based wind turbine, and a hybrid power source. For EVs itself, Fathabadi [53] proposed, designed, and constructed a battery/PV/wind hybrid power source for replacing the internal combustion engine with a small-size photovoltaic and a micro-wind turbine. According to the results, the renewable energy system can extend the cruising range by $19.6 \mathrm{~km}$. The power efficiency and the speed can be increased by $91.2 \%$ and by $121 \mathrm{~km} / \mathrm{h}$, respectively. Mobile renewable sources on vehicles have also attracted increasing attention among manufacturers, such as the Prius Prime by Toyota [68]. In 2010, when the Toyota introduced the 2010 Prius, the automaker provided an optional solar panel on the car roof. Furthermore, the Toyota automaker has further developed the latest 2017 Prius Plug-In (the Prius Prime) with the double cruising range than the previous model, meeting the daily commuting distance of drivers.

\subsection{Role of the electric grid for interactions between buildings and EVs}

In order to actualise the energy balance of the system, the function of the electric grid is to back up the energy demand of both the building and the EV during the renewable shortage period and to "absorb" the surplus renewable energy during the renewable surplus period as a virtual energy storage. The grid interaction is dependent on the realtime building energy demand, the renewable energy generation, the charging/discharging of the storage systems, and so on. Compared to the system without any EV integration, additional energy demands need to be considered when EVs are integrated with buildings, such as the energy consumption of transportation and the energy loss during the charging processes. Moreover, renewable energy generation, such as that of solar PVs, is negatively correlated with the energy demand from the annual and the diurnal aspects. This will lead to challenges for the energy interaction network, such as the high import/export stress on the electric grid and the high economic investment for grid maintenance and reinforcement. To the best of our knowledge, the export cost to the electric grid is generally cheaper than the import cost from the electric grid [72,73]. In some regions, surplus electricity is not allowed to be exported to the grid to avoid imposing an additional export stress on the grid. Integrating a home-charged plug-in electric vehicle (PEV) with buildings is regarded as an economic-competitive approach due to the capacity expansion of the battery storage. Moreover, a smart PEV charging/discharging schedule and smart DSM will increase the flexibility of the energy interaction network [3]. In addition, different energy sharing networks can be possible to interact with each other with the mobility and energy storage of the vehicle fleets. This section aims to review the function of the electric grid in the energy interaction network between buildings and EVs, and the realisation of energy interaction between different energy sharing networks. The contributions of energy storage systems, renewable systems, and the energy management control strategy on the smart grid have been reviewed under different energy interaction schemes, including building-to-grid (B2G), vehicle-to-grid (V2G), grid-to-vehicle (G2V), and grid-tobuilding (G2B).

In the available literature, several studies have focused on the role of the electric grid from several different perspectives, such as the energy balance, annual net operational cost, and environmental concerns. Kolokotsa [74] indicated that the efficiency and reliability of a smart grid can be enhanced through automated control, high-power converters, infrastructure for modern communications, sensing and metering technologies, and modern energy management techniques. In the academic world, the grid is also regarded as the boundary for grid interaction, the annual operational cost analysis, and the annual net equivalent $\mathrm{CO}_{2}$ emission. Thomas et al. [3] conducted a case study with respect to different renewable energy sources, EVs, and energy storage systems. The dynamic electricity imported from or exported to the grid multiplied by its hourly tariff is regarded as an objective for the daily cost analysis. Their results showed that, compared to the deterministic schedule of EVs, the total expected daily cost was lower in the stochastic approach. Meanwhile, the contribution of buildings and EVs to the electric grid has also been studied in the available literature. As a movable energy storage system, V2G interaction can stabilise both the voltage and the power of the electric grid via the operation of the EV battery [75]. Recently, researchers have focused on grid power stabilisation [33] and capability enhancement of the grid power supplementation [34]. In Portugal, to stabilise the grid power, Nunes et al. [33] predicted the impact of EV integration on the dependence on gas power plants in 2050. Their results showed that by integrating EVs for grid stabilisation, the gas share ratio is reduced from $10.2 \%$ to 0 and the surplus energy is reduced from $1.5 \%$ to 0 . Chakrabarti et al. [76] conducted an optimisation and analysis of system integration between electric vehicles and decentralised energy schemes in the UK. According to their results, revenue streams can be increased by about $11 \%$ when integrating commercial electric vehicles with local district heating system. In some regions where the electric grid is weak such as the islands [77], the mobile storage of the EV battery can support the weak grid and enhance the capacity of the electric grid for domestic usage. Colmenar-Santos et al. [34] indicated that by integrating EVs with buildings, the grid's capability can be enhanced in terms of supporting domestic usage. In regard to buildings' contribution to the electric grid's stability, Lawrence et al. [45] indicated that the contribution of buildings to the grid's stability was dependent on both the smooth operations of the building energy systems and interoperable data exchange technique. However, it is problematic to integrate the new controller and advanced technologies with buildings due to the mismatch between older HVAC systems and advanced building control technologies. Kolokotsa [74] demonstrated the flexibility provided by buildings to the smart grid framework with flexible building demand. 


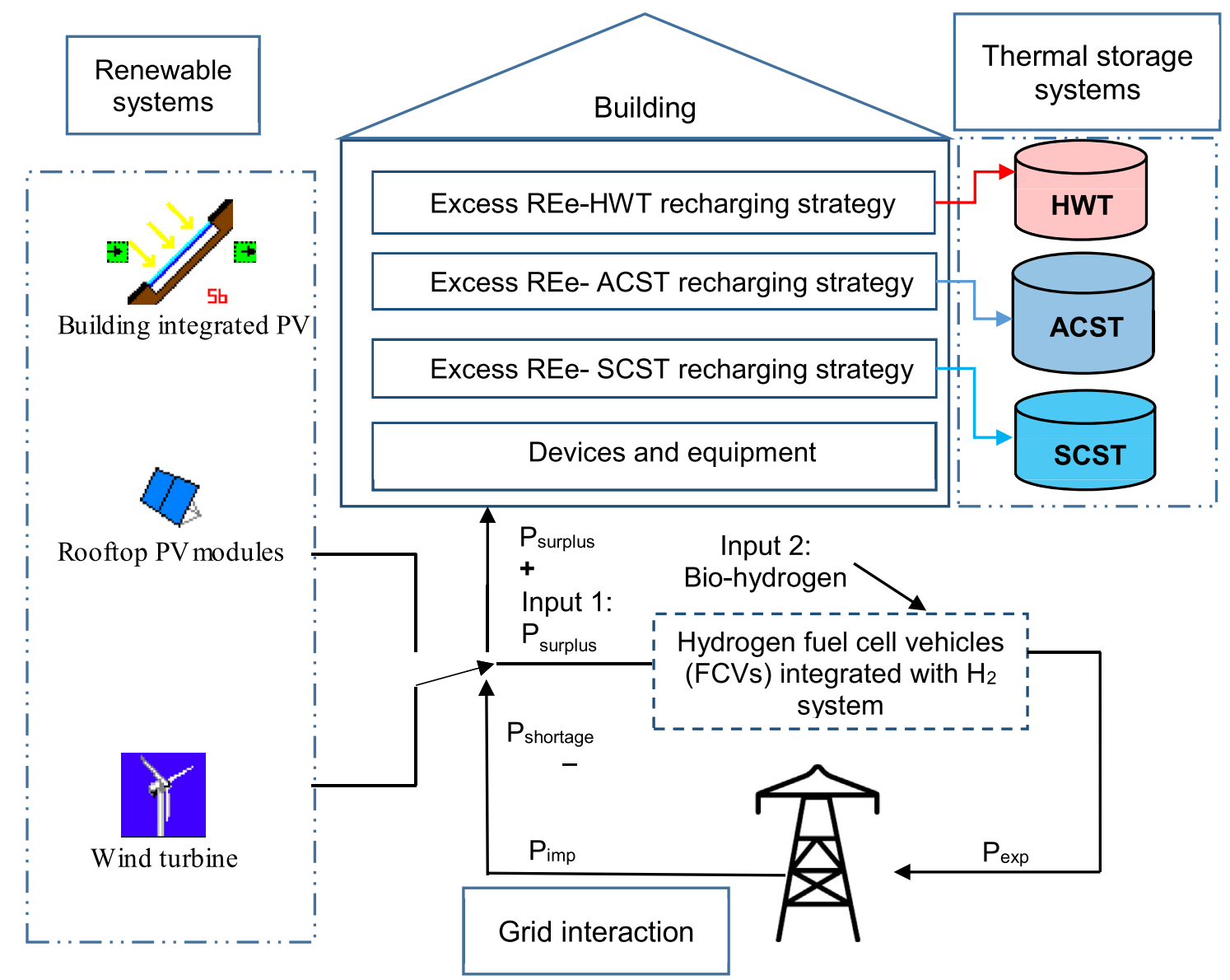

(a)

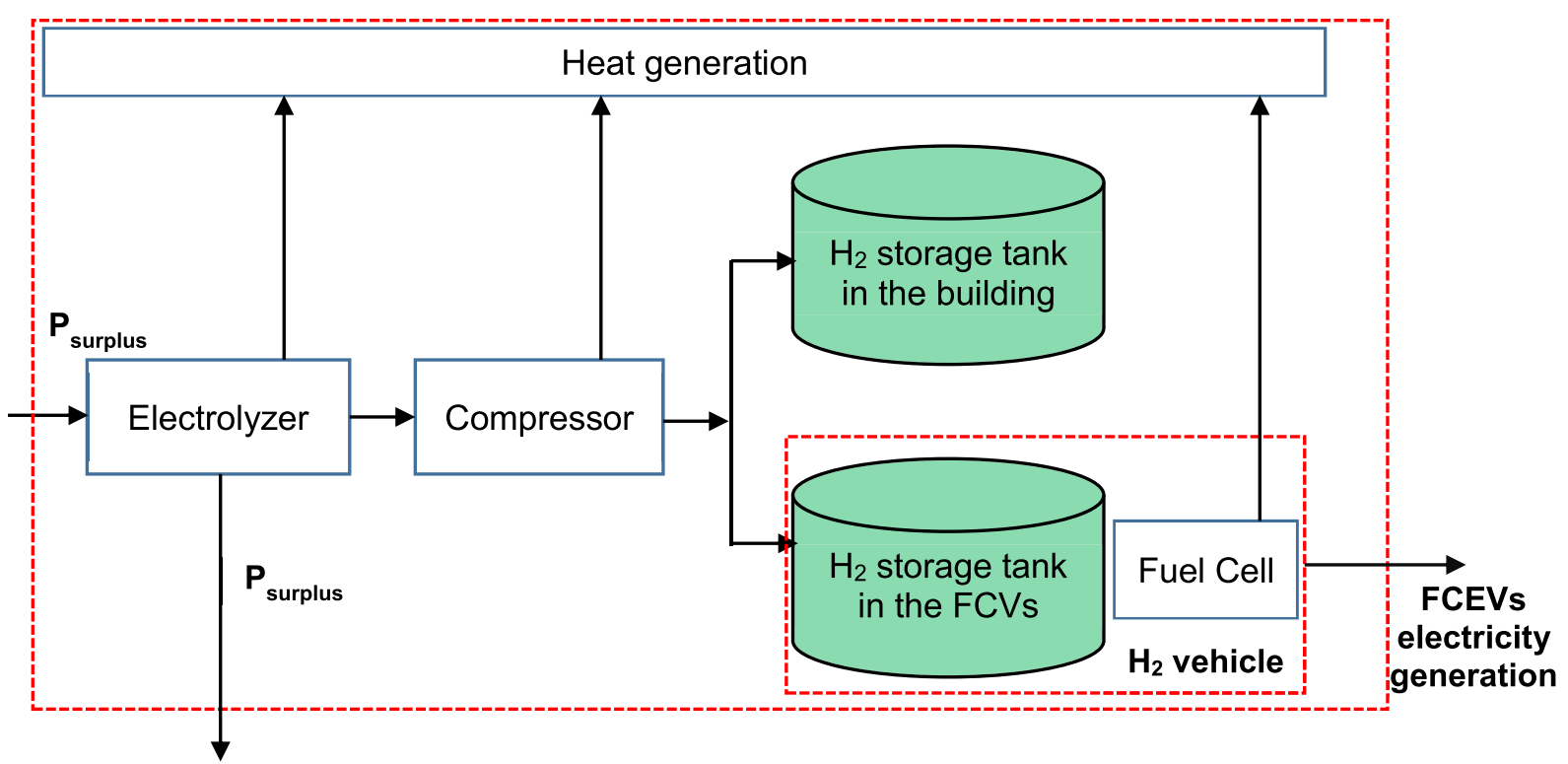

(b)

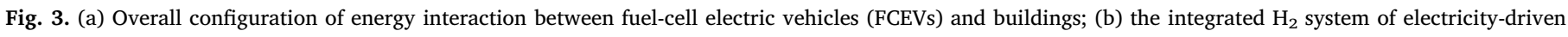
hydrogen FCEVs.

Their research gives an insight into the benefits that buildings and communities can provide to stabilise power and to improve the fast response of smart grids. From the perspective of energy interaction, renewable energy penetration and the annual matching capability are dependent on the energy control strategy. Some researchers focused on the optimisation of the energy control strategy, as shown in Refs. $[37,44,47]$. In general, the optimisation of control strategy can utilise various aspects, such as smart buildings [47], the renewable system [43], EV integration [37], and the smart grid [44]. From the perspective of both buildings and the renewable system, by optimising the 
Table 3

Summary of the assessment criteria of the energy interaction network between buildings and HVs.

\begin{tabular}{|c|c|c|c|}
\hline Assessment criteria & Energy & Environment & Economy \\
\hline Metrics & $\begin{array}{l}\text { Energy balance }[12,21,46,71] \text {; Grid interaction }[12,13,21] \text {; Annual energy } \\
\text { matching capability }[12,21,40]\end{array}$ & $\begin{array}{l}\text { Equivalent } \mathrm{CO}_{2} \text { emission } \\
{[12,14,40]}\end{array}$ & $\begin{array}{l}\text { Annual net operational cost and net present } \\
\text { value [14] }\end{array}$ \\
\hline Interaction mode & \multicolumn{3}{|c|}{ Zero-emission building integrated with a zero-emission hydrogen vehicle $[12,14,21,40]$} \\
\hline
\end{tabular}

operational strategy, Jin et al. [35] addressed the uncertainty and the intermittence of the building demand, the outdoor environment, and renewable generation. Their proposed strategy was validated to be robust in terms of reducing the annual net operational cost, smoothing the power curve, and ensuring both indoor thermal comfort and the energy demand for transportation. Bulut et al. [47] proposed the concept of the active building associated with energy demand flexibility. However, further development of their proposed concept is constrained by the expensive investment. On the basis of a study on the integration of green cars such as hydrogen cars and electric cars with sustainable cities in the southeastern section of France, Islam [43] indicated that PVs were more promising than other renewable systems in terms of the grid interaction, the annual net operational cost, and the annual net emission. Their results showed that by integrating PVs and integrating green cars with office buildings, the imported electricity from the grid is reduced by more than $43 \%$, and the electricity cost is reduced by $10 \%$. Moreover, the total annual net emission to the environment is reduced by more than $90 \%$. From the perspective of EVs, on the basis of a heuristic algorithm, Umetani et al. [37] developed a linear programming to intelligently charge and discharge batteries. Moreover, the impact of the smart charging/discharging schedule of EVs on the peak load reduction has also been investigated. The study results showed that regardless of the limitation of the net feed-in tariff system, the computational results provide an incentive to individual enterprises to integrate EVs with buildings.

\subsection{EMS including buildings, EVs, and grid}

In order to enhance the energy performance with respect to different performance assessment criteria, it is essential to strategically control the EMS. In general, there are several different EMSs for different renewable systems, diversified energy conversions, hybrid energy storage systems, different vehicle interactions, and different energy control strategies. In order to enhance the annual matching capability between renewable energy and the total energy demand, technical solutions have been investigated by researchers, such as distributed EMSs [78], home demand-side management [79], renewable systems, and energy-efficient technologies such as the GSHP and the solar thermal collector system [21]. The total energy demand can be made flexible through the operation of the hybrid storage systems $[3,37,44]$ and the passive energy storage system, such as the utilisation of the thermal mass of the building envelope [80]. With respect to different performance assessment criteria, flexible energy demand can also be achieved on the basis of grid information, such as the dynamic grid feed-in tariff [81] and the dynamic equivalent $\mathrm{CO}_{2}$ emission factor of the electric grid $\left(\mathrm{CEF}_{\mathrm{eg}}\right)$ [84]. Moreover, to enhance the energy interaction between vehicles and buildings, several researchers have also focused on the optimisation of the EV travelling schedule [3,26].

Cao et al. [21] investigated the performance of a hybrid zero energy system including the renewable system, a ZEB, a zero-energy vehicle, and energy-efficient technologies such as the GSHP and the solar thermal collector system. Their results showed that the GSHP was beneficial for realising net zero energy balance and improving the overall matching capability. In order to support the EMS by levelling the building energy demand, Aziz et al. [85] investigated the impact of PV-hybrid storage systems (the EV battery and the re-used battery) on the building electric demand. Their results showed that by strategically controlling the charging and the discharging of the EV battery, the peak electric demand can be successfully shifted to the valley period. Moreover, by setting the threshold for cutting the electric demand, the re-used battery is more effective than the EV battery in terms of flattening the peak load. In the office building, Jin et al. $[35,86]$ proposed a hierarchical energy management strategy by regarding the EVs as a flexible energy storage system. Their results showed that the daily operational cost can be reduced at the day-ahead dispatch stage and the electric power exchanges are flattened at the intra-hour adjustment stage. The concept of DSM has also been proposed and studied by Mesarić et al. [79]. According to the results, the DSM has been verified to be effective and useful in terms of maximising renewable energy penetration, and optimising both the schedule for charging/discharging the EV battery and the time duration for operating service facilities of the building. Moreover, regarding stand-alone buildings, the impact of demand management strategies on the performance of the off-grid building has also been investigated. For instance, Sehar et al. [23] investigated the impact of renewable energy and the integration of EVs in terms of discharging the EV battery for domestic usage. According to the results, compared to the only demand-side control strategy, the power from the plug-in EV being discharged for domestic usage can be increased from $7 \%$ to $38 \%$ via the operation of the demand-side control strategy and integration of the solar PV. Rahbari et al. [36] developed a new controller using an adaptive intelligent control strategy to address the mismatch between renewable energy and the energy demand. The studied EMS includes the traditional energy generation system (power plant), the distributed/renewable generation unit (PV and wind turbine), and the mobile energy storage system (EVs). According to the results, the proposed controller was found to be more useful than other controllers in terms of optimising the charging/discharging schedule of the EV battery, sizing, and siting the parking lots of EVs. The passive energy storage of the building envelope has also attracted researchers' attention in terms of modulating the building demand. For instance, in order to utilise the flexibility provided by the building envelope, Dréau et al. [80] have proposed a control strategy based on the utilisation of the thermal storage and heat conservation of the building envelope. According to their results, compared to active storage systems such as the battery and the thermal storage tank, a control strategy based on passive storage was mainly dependent on the insulation, the emitter, and the local weather conditions. From the perspective of the operational cost, energy control strategies in the EMS have also been investigated in accordance with the real-time price of electricity. In terms of the DSM in commercial buildings, Wang et al. [81] investigated the effect of the stationary battery EMS and EV integration on the cost savings in accordance with the dynamic electricity price. Their research shows that, the stochastic DSM is more economically competitive than the deterministic DSM in terms of adapting to various load patterns, different renewable capacities, and various electricity prices. Wu et al. [82] optimised the battery size for a smart home by using convex programming and analysing the historical electrical energy data of three different homes located in California and Texas. The comparison between the optimal results of the three different homes was conducted in respect to various time horizons, maximal values of power to grid, prices of battery energy storage systems, and home electricity use/demand patterns. According to their results, the optimal battery energy capacity and the maximum power for the three homes were independent of the charger price. Lazzeroni et al. [83] optimised the 
optimal battery management for vehicle-to-home and vehicle-to-grid operations, in terms of whether the excess PV generation was either used to charge batteries or to partially cover the energy demand of the house. According to their results, the annual cost saving can be around $25-30 \%$, together with the increase of self-consumption of the PV production.

The optimal operation of the EMS has also been investigated in the literature. These optimisation approaches can be from the perspectives of the renewable system [3], the charging/discharging schedule of the EV battery [3,37], and smart buildings [81]. Thomas et al. [3] conducted an economic analysis of the hybrid energy system including the renewable system, EVs, and energy storage systems. According to the results, compared to the basic case study, the total cost of the system increased more evidently when there were no energy storage systems. Umetani et al. [37] optimised the schedule for charging and discharging the EV battery in a building EMS. From their results, the peak load was reduced by coordinating the charging and discharging processes of the EV battery. Furthermore, the uncertainties of both the building demand and the departure time of EVs were addressed by the developed twostage heuristic algorithm. Salpakari et al. [87] proposed a cost-optimal control strategy for energy management of the hybrid PEVs-building system. According to their results, both the annual operational cost and the grid interaction can be reduced by implementing a cost-optimal control strategy. Furthermore, compared to the space heating load control system, more flexibility can be provided by the PEV control strategy. However, the additional battery degradation decreases the economic competitiveness of the V2G. Wu et al. [88] developed an optimal energy management strategy for a smart home, integrating the $\mathrm{PEV}$, renewable energy, and home battery. According to their results, when implementing the optimised battery energy storage system, the home did not need to buy electricity from the grid during peak periods. Wu et al. [89] investigated the stochastic control of a smart home energy management, integrating the PEV and the photovoltaic array. The stochastic model integrated a Markov Chain model of PEV mobility, and predictive models of home power demand and PV power generation. According to their results, in comparison with no optimal control case, the cost saving ratio was $493.6 \%$ for a Tesla Model S and $175.89 \%$ for a Nissan Leaf, when implementing the optimal stochastic dynamic programming.

Moreover, several researchers investigated the EMS between multicombined district microgrids in the community. The concept of the district EMS (DEMS) was first proposed in References [90,91]. Fanti et al. [90] focused on the decrease of the electricity imported from the electric grid by optimising the capacity of the renewable systems, the thermal storage system, and the districts' EVs. Both deterministic and stochastic models for renewable energy generation have been developed and implemented in their research. Their results showed that the DEMS can provide incentives to policymakers for the energy management of cooperative microgrids. As shown in Fig. 4, Mirakhorli et al. [91] proposed a model predictive controller for connecting the smart home and the smart grid. The controlled components include the smart HVAC, smart EV, smart water heater, and smart PV. A smart meter was installed at the grid-home interface to send the signal to the electric grid. Their results showed that in comparison with the traditional rulebased control, the proposed price-based and behaviour-based control strategies can increase the cost savings to $30 \%$ and to $42 \%$, respectively.

\subsection{Discussion on real applications and future potential}

Regarding the energy integration and interaction between buildings and EVs, several critical techno-economic issues need to be considered before the energy interaction technology can be widely accepted in the market. Firstly, in an EV integrated energy sharing network, if there is no economic incentive or subsidy for the depreciation of the EV battery, vehicle owners may be reluctant to additionally charge their vehicles due to the degradation of the EV batteries. Secondly, as there are different commercial products of EVs on the market, there are several critical points which should be further considered, such as how to seamlessly integrate the EVs with the building energy systems, and how to provide reliable power during critical periods. Therefore, depending on the type of EVs and buildings, a standardized building-EV interface needs to be defined and set up. Moreover, the standardization of the $\mathrm{B} 2 \mathrm{~V}$ and $\mathrm{V} 2 \mathrm{~B}$ interactions is still missing. Thirdly, regarding buildings integrated with hydrogen-fueled FCEVs, the social acceptance of the security of the high-pressure hydrogen storage tanks should be improved. Lastly, with an increase of the integration of EVs into the local or regional grid, the electric grid may suffer from the instability and fluctuation of the V2B and B2V loads. This may require capacity expansion of the electric grid as well as updating of the energy management strategies and controls in the local or regional energy systems.

\section{Energy interactions between buildings and fuel-based vehicles}

\subsection{Buildings and conventional gasoline-based vehicles}

The conventional gasoline-based vehicle can be integrated with buildings with respect to different energy forms, advanced energy conversions, and diverse energy storage systems. The internal combustion engines (ICEs) in the gasoline-based vehicles can provide both electrical and the thermal energy for domestic usage [93], such as heatrecovered electricity, domestic hot water (DHW) heating energy, and

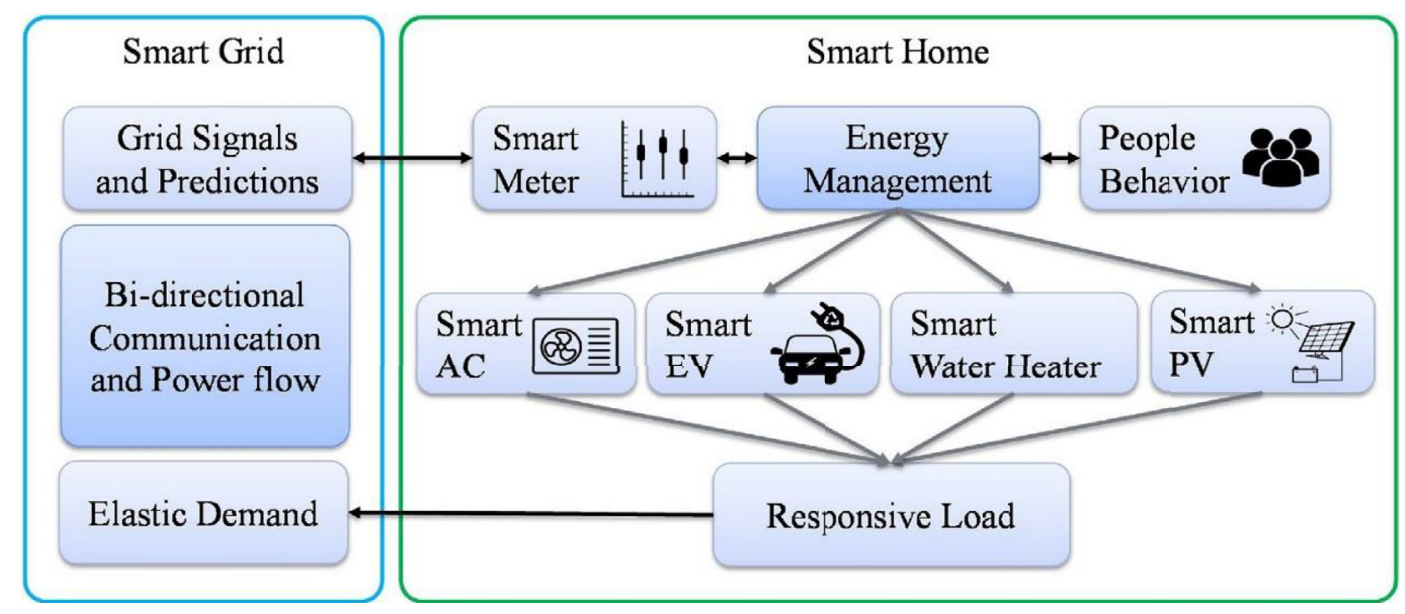

Fig. 4. Overview of the smart building to the smart grid interaction [91,92]. 
both heating and cooling energy. Depending on different heat recovery techniques, such as the thermal-to-thermal recovery and the thermal-toelectrical conversion, the exhaust heat can be recovered to either thermal or electrical energy. However, there are few studies that investigate the energy interaction between gasoline-based vehicles and buildings. Moreover, technical solutions for realising the energy interaction are not straightforward. The impact of the energy interaction between the gasoline-based vehicle and the buildings on the building energy demand has not been quantitatively studied yet. In this section, the available technologies are firstly reviewed in terms of recovering the exhaust heat from ICEs with respect to different energy forms and advanced energy conversions. Afterwards, an energy interaction network is formulated to realise the energy interaction with advanced technical solutions. Meanwhile, several challenges for realising sustainable and efficient interactions have been demonstrated as avenues for future research. Furthermore, a discussion for real application and future potential has been included to indicate benefits from inclusion of additional work in the future.

The feasibility of ICEs for domestic usage has been studied by Ehyaei et al. [93] from the perspectives of the exergy, the economy, and the environment. As shown in Fig. 5, in winter, ICEs can be operated to generate electricity in order to cover the electric load of both electrical appliances and light bulbs, and the electric demand of heat pumps. The recovered heat in the exhaust heat exchanger can be used to cover the remaining heating load. In summer, in addition to covering the electric demand, the ICEs can partially cover the cooling load via mechanical cooling. Moreover, the remaining cooling load can be covered by the absorption chiller driven by exhaust gas.

On the basis of the research results related to the technical feasibility of ICEs in residential building applications [93], it is possible to integrate gasoline-based vehicles into buildings, even though few studies focus on this topic in the literature. In regard to gasoline-based vehicles, the energy recovered from ICEs in the vehicles can be either thermal or electrical energy. Compared to the ICEs implemented in buildings, the recovered energy from gasoline-based vehicles' ICEs is dependent on the travelling schedule of the vehicles. A schematic diagram of an integrated system, formulated in this study in terms of recovering exhaust heat in gasoline-based vehicles' ICEs, is shown in Fig. 6. The cooling water first enters the engine cooling water heat exchanger for heat extraction in the engine unit. Afterwards, it enters the DHW tank for the DHW heating usage. Meanwhile, the power generation efficiency of the engine unit can be improved due to the reduced operating temperature. In regard to the heat recovery technologies as shown in Fig. 6, the exhaust heat from the ICEs can be recovered for DHW heating. This process can be seen in both the academia [93] and industrial worlds [95,96]. Moreover, for cooling energy purposes, the exhaust heat can be used to drive either the absorption or the adsorption chiller [97]. By recovering the waste heat of the compression phase of the liquefaction cycle to drive the absorption chiller, the specific cooling energy consumption is reduced, and the exergy efficiency of the whole system can be increased [98]. As shown in Fig. 6(b), the exhaust heat can also be recovered to electrical energy via the thermoelectric device, the Organic Rankine Cycle, and the turbocharger. The conversions of the recovered exhaust heat to both thermal and electrical energy make the energy interaction between gasolinebased vehicles and buildings promising and techno-economically competitive. However, the application of this energy conversion is restricted by the low energy conversion efficiency [99]. A new energy interaction network between gasoline-based vehicles, buildings, and the grid, is formulated as shown in Fig. 6(a) for real application in cooling-dominated regions. In addition to the recovered electrical energy, electricity can also be generated from the solar PV/T system. In order to cover the heating load considering the intermittence of both the renewable source and the hot water from the PV/T system, the fuel-
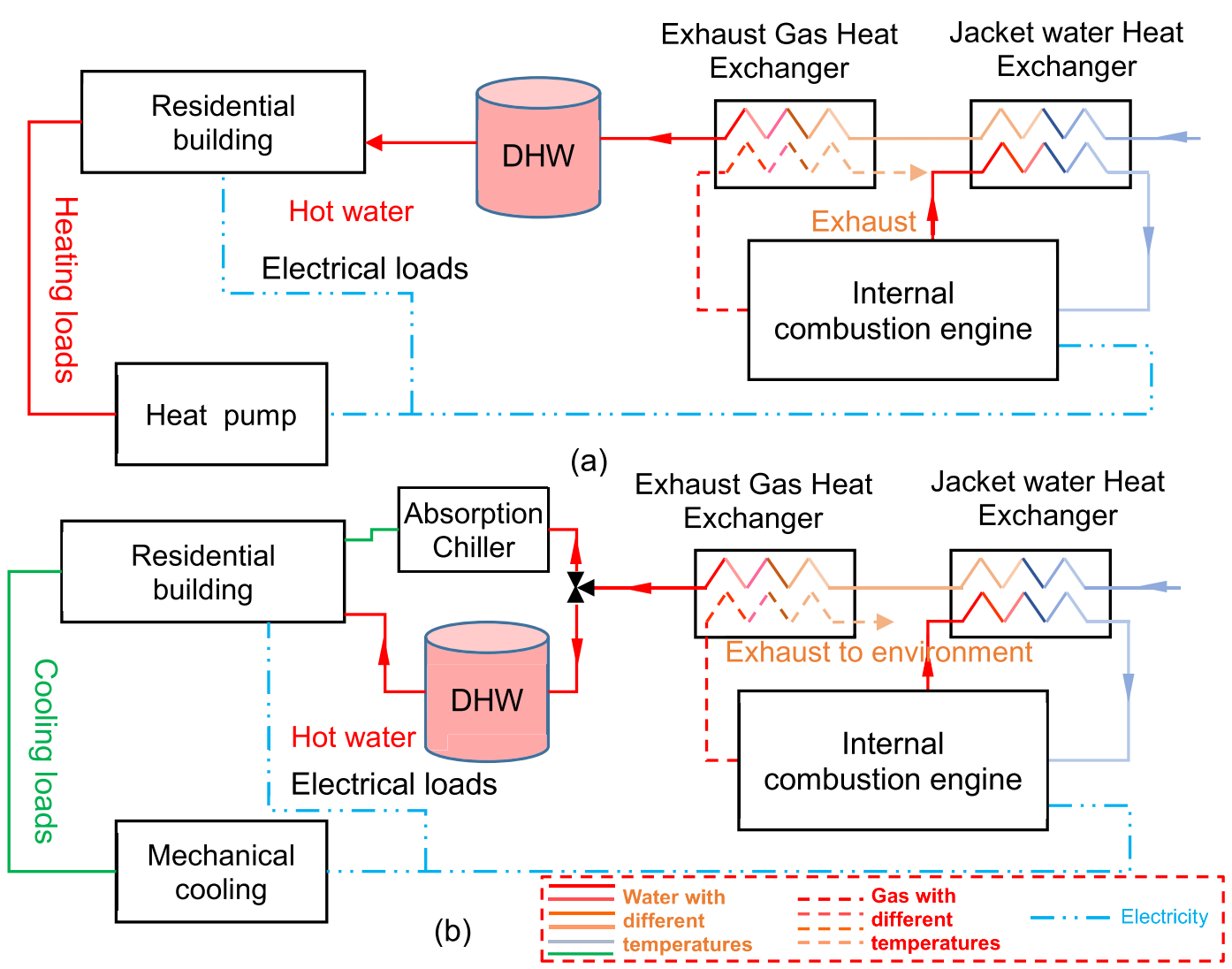

Fig. 5. System configuration to meet the energy demand of a residential building [93,94]: (a) winter, (b) summer. (Note: different colors of lines indicate different temperatures.). (For interpretation of the references to color in this figure legend, the reader is referred to the Web version of this article.) 


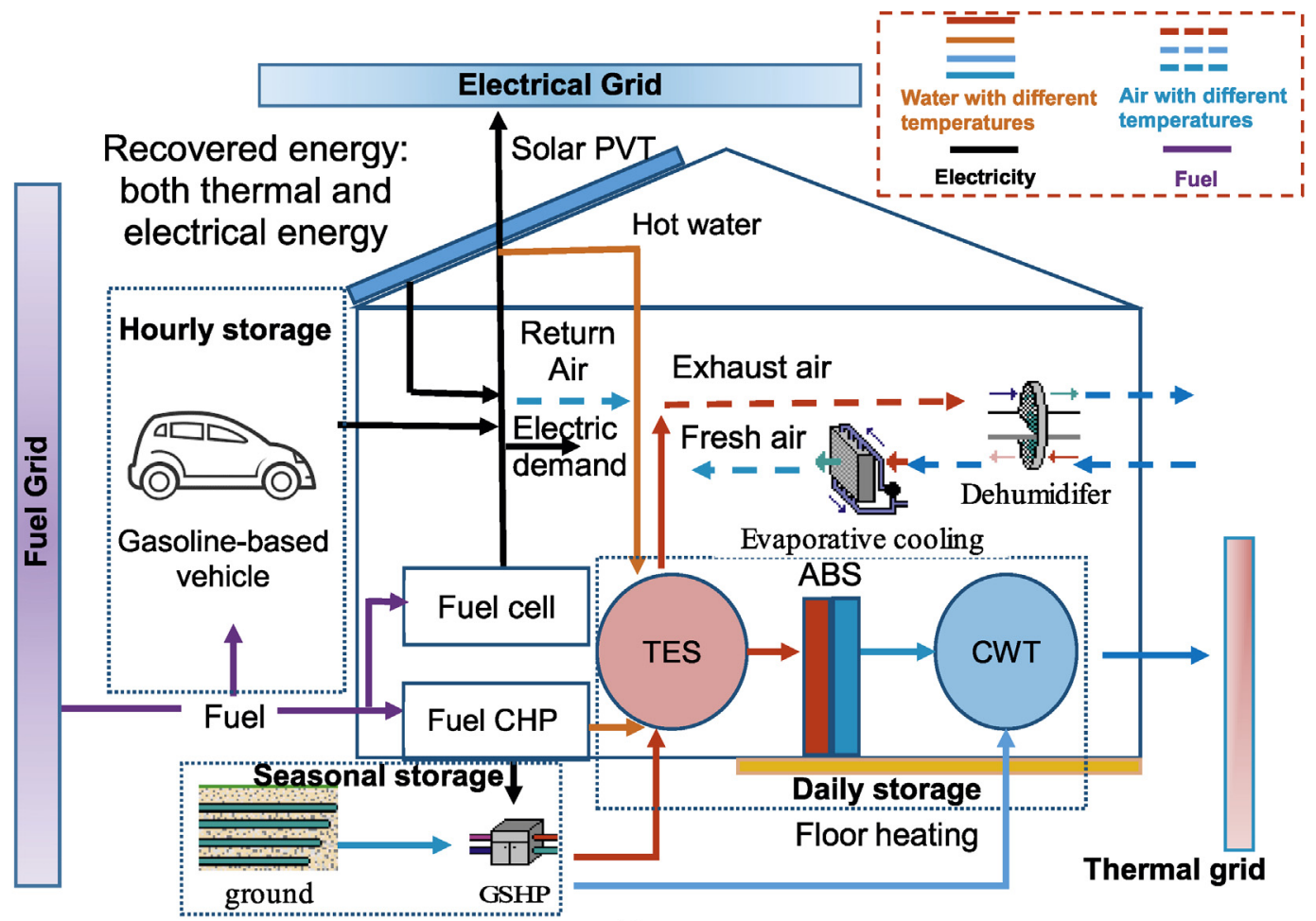

(a)

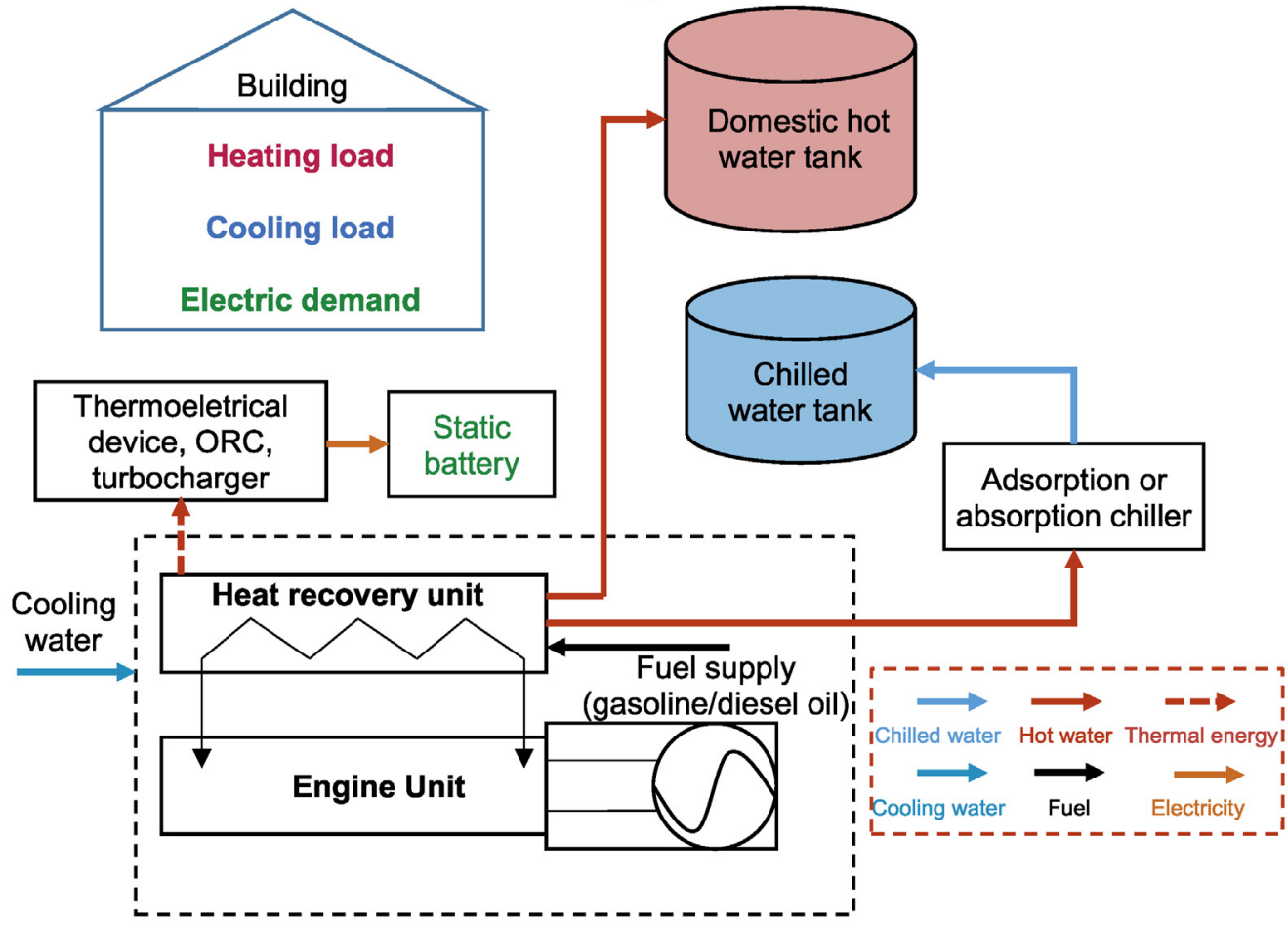

(b)

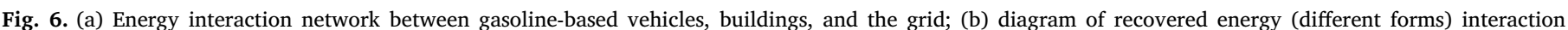

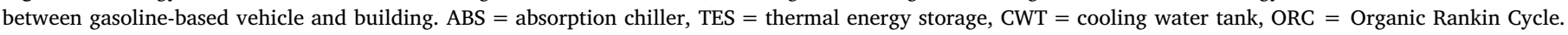

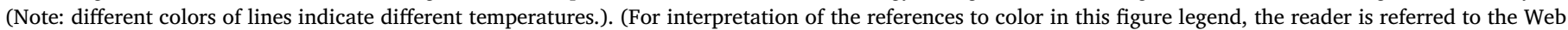
version of this article.)

based CHP system and the GSHP are implemented. Thermal energy is stored in the thermal energy storage tank. For the daily storage purpose, hybrid energy storage tanks are designed, including the thermal energy storage tank and the cooling water storage tank (CWT). The ground is designed for the seasonal storage purpose, which is charged and discharged by the GSHP. In order to realise energy balance between the total energy released into and absorbed from the ground, several technical solutions can be adopted with respect to different climatic conditions. For example, in the cooling-dominated region, the implementation of an absorption or adsorption cooling system can convert 
heating energy to cooling energy. Moreover, an evaporative cooling system is also feasible for the energy balance as thermal energy can be used to heat the exhaust air, which can dehumidify the outdoor fresh air. Moreover, in regard to the formulated system, different energy control strategies can be proposed from the perspectives of the driving schedule of the gasoline-based vehicles, the operating control strategy of the HVAC systems, renewable systems, and energy storage systems.

For the gasoline engine, it is reported that $30 \%-40 \%$ of the waste heat during the thermal combustion process is sent to the environment via the exhaust pipe [100]. This results in high GHG emission to the environment due to the gasoline combustion. In addition, the ratio of the engine power to the total fuel energy is only $10.4 \%$, whereas $27.7 \%$ is lost through the exhaust gas. The remaining $61.9 \%$ includes the friction loss, the coolant loss, and so on [101]. A similar magnitude of energy loss from the exhaust gas can also be seen in Ref. [102]. To reduce the thermal energy loss with heat recovery techniques, several studies have concentrated on enhancing the heat recovery efficiency through innovative design of the diesel engine's configuration. For instance, Dolz et al. [102] designed different configurations of the heavyduty diesel engine to enhance the heat recovery efficiency with respect to the single cycle, the binary cycle, and different temperatures of the heat sources, respectively. The energy performance and the recovery efficiency of each configuration were comparatively investigated. Compared to the energy performance of the other configurations as listed in Table 4, the binary cycle showed the most promising potential in terms of both the total recovered thermal energy and the fuel consumption savings. Meanwhile, Wang et al. [103] indicated that exhaust energy recovery can improve the engine fuel conversion efficiency by $8 \%-14 \%$ and reduce the total fuel consumption by $34 \%$.

In regard to the exhaust heat recovered from the ICEs for electricity generation, three technologies are available: thermoelectrical devices [15], the Rankine cycle [16], and the turbocharger system [17]. Table 5 summarises advanced technologies for recovering exhaust heat from ICEs together with the anticipated objectives. Readers are highly recommended to refer to the listed references for more detailed information.

Regarding the exhaust heat recovery for the electricity generation, there are limited studies focusing on the integration of exhaust heat recovery with buildings. Furthermore, few studies explicitly indicate whether the power generated from the exhaust heat recovery system in vehicles can be utilised for buildings. A schematic system for recovering exhaust heat to partially cover the building demand has been formulated, and challenges for the realisation of sustainable and efficient energy interactions have also been proposed in this study. Exhaust heat recovery of gasoline-based vehicles can be promising, especially with respect to the enhancement of the recovery efficiency, the decrease in the cost of thermal-electrical (TE) materials, the adoption of nanofluid into the thermoelectric generation system, and the replacement of the weight turbine and the weight compressor by nanomaterials. In terms of the energy interaction between buildings, gasoline-based vehicles, and hybrid grids, avenues of research for future studies are the schematic system configuration and the energy control strategy in different climatic regions.

\subsection{Buildings and biofuel-based vehicles}

Compared to gasoline-based vehicles, biofuel-based vehicles tend to be more promising in terms of environmental protection as biofuelbased vehicles are driven by renewable energy with less emissions to the environment. However, the popularisation of the biofuel-based vehicle is constrained by the availability of sustainable biofuels. Currently, depending on the type of biofuel, there are three types of biofuel-based vehicles in the vehicle market: flexible fuel vehicles (running on gasoline blended with ethanol fuel), diesel vehicles (running on biodiesel), and fuel-cell vehicles (running on bio-hydrogen). The development history and current market share of each type of vehicle have been specifically reviewed by Chang et al. [117]. Moreover, Chang et al. [117] also provided detailed information on the production of bioethanol, biodiesel, and bio-hydrogen. As the focus of this section is mainly on the energy interaction between buildings and biofuelbased vehicles, the production of biofuel and its development history are not introduced here. Table 6 lists the energy interaction between three biofuel-based vehicles and buildings with respect to different energy forms. As three exhaust heat recovery technologies from ICEs have been specifically described in Section 4.1, here the main focus is on the biofuel in the vehicle to drive the biofuel boiler, the biofuel CHP, and other biofuel-based equipments. For instance, Chen et al. [118] concluded that compared to the conventional engine-based CHP, dieselbiofuels can improve the CHP efficiency from $45.77 \%$ to $57.97 \%$.

In regard to the heat recovery in fuel cells, adsorption systems [119] show promising prospects in terms of both electrical and cooling energy cogenerations. According to Reference [119], the heat recovery efficiency can be further enhanced with respect to higher power outputs and shorter cycle times of the fuel cell. Under the testing condition in the study, the output cooling power exceeds $400 \mathrm{~W}$ when the output fuel-cell power is between 600 and $1400 \mathrm{~W}$. The overall efficiency can go up to $63 \%$ when the cycling time-duration is $40 \mathrm{~min}$. The specific configuration of the system in the studied case is shown in Fig. 7. The proton exchange membrane fuel cell is cooled by water, which transfers the heat to the thermosyphon. On the chiller side, the heat from the thermosyphon is delivered to the reactors by the heat transfer fluid (water). Black lines represent circuits concerning the next cycle, where reactor 1 is cooled and reactor 2 is heated.

Apart from recovering the heat from the fuel cell for thermal energy, the heat can also be recovered in the form of electricity by employing thermoelectric materials or generators [121]. Zhang et al. [122] proposed a new hybrid system for enhancing the energy performance of solid oxide fuel cells (SOFCs). In comparison with the stand-alone SOFC, the power density and efficiency of the proposed system increased by $2.3 \%$ and by $4.6 \%$, respectively. However, the energy interaction with the advanced heat recovery technology has not been investigated in the current literature. To bridge the research gap, a systematic energy interaction network is formulated for the potential energy interactions between biofuel-based vehicles, buildings, and hybrid grids.

Fig. 8 demonstrates the formulated energy interaction network between biofuel-based vehicles, buildings, and hybrid grids. Biofuels from the biofuel grid can be used for transportation. The biofuel cell and the biofuel cogenerated cooling and power facility can generate electricity to partially cover the building demand. Moreover, the electricity

Table 4

Results for different configurations of the heat recovery system [102,104].

\begin{tabular}{|c|c|c|c|c|}
\hline Configurations & Output power $(\mathrm{kW})$ & Power increment (\%) & Heat transfer $(\mathrm{kW})$ & Fuel Consumption reduction (\%) \\
\hline Reference configurations & 311 & - & 357 & - \\
\hline All heat sources: water Rankine cycle & 342 & $10.00 \%$ & 868 & $8.80 \%$ \\
\hline All heat sources: binary cycle & 370 & $19.00 \%$ & 938 & $16.00 \%$ \\
\hline High temperature heat sources: water Rankine cycle & 357 & $14.70 \%$ & 729 & $8.50 \%$ \\
\hline
\end{tabular}


Table 5

Technologies for recovering the exhaust heat from ICEs.

\begin{tabular}{|c|c|}
\hline Heat recovery technology & Thermoelectrical devices [15,105,109]; Rankine cycle [16,102]; Turbocharger system [17] \\
\hline Solutions & Structural design $[15,109]$; radiator $[110,115]$ and the exhaust gas systems $[110-112]$; TE materials $[113,114,115]$ \\
\hline Research objectives & $\begin{array}{l}\text { ICEs' efficiency [114]; Exergy efficiency [116]; Energy demand reduction [96,114]; Equivalent emission [116]; Sustainability index [116]; Solar } \\
\text { energy generation [105,106] }\end{array}$ \\
\hline
\end{tabular}

generation source also includes a solar PV/T system. The generated electricity can be used to meet the basic electric load, such as lighting, the equipment, and the devices. Furthermore, the electricity can also be used to drive the GSHP to generate thermal energy. The surplus electricity can be converted into electrofuel, which can be sold to the biofuel grid for the economic benefits by residents. In order to cover the heating demand of the building, the hot water (from the PV/T system, from the biofuel cell and from the GSHP) is stored in the thermal energy storage tank (TES). Both TESs and CWTs are used for daily storage purpose. In the hot summer and cold winter regions, both the radiative cooling wall and the under-floor heating system are designed to meet the indoor thermal comfort requirement. Based on the formulated EMS as shown in Fig. 8, several anticipated positive results can be made, whereas further research studies need to be conducted to justify the techno-economical feasibility. First, different energy conversions and hybrid energy storage systems (the hourly biofuel storage vehicle, thermal storage tanks, and the battery) can reduce the energy interaction between buildings and hybrid grids. Thereafter, the hybrid grids' interactions can be mitigated, together with the decrease of economic costs related to the initial investment, operation and maintenance. Second, on-site renewable energy can be used to stabilise the pressure level of the hybrid grids. As a result, the capability of the hybrid grids can be further enhanced by the renewable system in terms of both domestic usage and transportation. Third, in regard to the stochastic scheduling of vehicles, the uncertainty of the renewable generation, and the dynamic building load, an optimised energy control strategy can also increase the building energy performance and reduce the operational cost.

\subsection{Discussion on real applications and future potential}

Regarding the energy integration and interaction between buildings and fuel-based vehicles, several critical concerns should be considered. Firstly, the low heat recovery efficiency, and the depreciation of fuel cells and internal combustion engines are main concerns from stakeholders' perspectives for being motivated to participate in the energy sharing network. The development of advanced heat recovery material and innovative design of diesel-engine configurations can be effective solutions for the enhancement of the heat recovery efficiency. The subsidy from governments to fuel-based vehicles' owners may encourage vehicles' participation in the energy sharing network. Secondly, regarding the buildings integrated with fuel-based vehicles, the fire safety, security, and compatibility for the exchange and sharing of the fuels should be appropriately addressed. The standardized piping system for the transmission and exchange of fuels between buildings and vehicles should be developed. Thirdly, regarding the heat recovery from vehicles to buildings, the current technology is immature, especially considering the considerable heat loss from the combustion engine to the environment. Development and implementation of portable energy storage systems with high energy storage density in vehicles, will be promising in respect to this technical problem.

\section{Current capabilities of the building side for compatibility with the vehicle}

With the rapid development of the EV industry in the past several decades, installing electric charging facilities in buildings has become more popular than ever before [65]. For example, in Hong Kong, the total number of EVs was only 74 in 2010 [123]. However, the total number of registered EVs was 3000 in 2018 [124]. Moreover, to encourage the use of the net zero energy/emission vehicle (NZEV), the Hong Kong government gives a tax break of up to HK\$ 250,000 [125]. The total number of public chargers increased from 1036 in 2013 to 1774 in 2018. The total number of both public and private quick chargers increased from 66 to 880 across the 18 districts in Hong Kong [126]. Considering the increased energy consumption and environmental emissions, the increasing number of both the charging facilities and EVs makes it necessary and beneficial to integrate the vehicles with buildings. From the perspective of the electric vehicle, the basic principle for the energy interaction is to charge the EV battery with the surplus renewable energy and to discharge the battery for both domestic usage and transportation when required [127]. In the academic world, the energy interaction between buildings and EVs is mainly focused on improving the charging efficiency by optimising the EV schedule $[117,128]$, the parking time and the distribution of parking lots [129], the EMS, and the energy control strategy [79]. Moreover, the HV has attracted researchers' attention recently due to its environmental friendliness when $\mathrm{H}_{2}$ is generated by the renewable system $[14,40]$. Furthermore, buildings with massive production of biomass and biowaste, such as agricultural buildings or buildings close to the forest, can generate various types of biofuels through both chemical and biochemical processes. By optimising the energy control strategies and sizing both the renewable capacity and the storage systems, the EMS, consisting of the biofuel generation building, the biofuel-based vehicles, and the biofuel grid, can reduce the fuel interaction with biofuel grid, the annual emission, and the annual operational cost. This section mainly reviews the energy interaction between buildings and different types of vehicles from the building side. The critical question is afterwards proposed whether buildings are compatible with the vehicles under current situation. Furthermore, discussion in the real application and future potentials have been conducted to indicate benefits from inclusion of additional work in the future.

\subsection{Interaction between electric/hydrogen vehicles and buildings}

The objective of the net ZEB is to transform buildings from the traditional consumer to a prosumer by employing renewable energy sources. The large capacity of renewable systems can further enhance the capability of buildings to interact with vehicles. For instance, Cao et al. [40] showed that in Helsinki, a 14-kW wind turbine can realise a nearly ZEB with full annual availability of the $\mathrm{H}_{2}$ vehicle, whereas a $178-\mathrm{m}^{2} \mathrm{PV}$ can realise a net ZEB with 48 days' annual unavailability of the $\mathrm{H}_{2}$ vehicle. Moreover, the energy-efficient technologies (the solar thermal collector, GSHP, and so on) will contribute to the enhanced energy matching capability and techno-economic feasibility [131]. Further, the development of highly interactive DSM systems and advanced energy control strategies from the perspective of the buildings can also enhance the energy interaction [23,79]. For instance, Sehar et al. [23] concluded that by adopting both the demand control strategy and renewable systems, the absorption of the plug-in EV penetration at the building level will be increased from $7 \%$ to $38 \%$.

With respect to the energy generation system, in addition to the renewable generation system, the domestic combined CHP can also be regarded as an effective solution for covering the transportation energy 


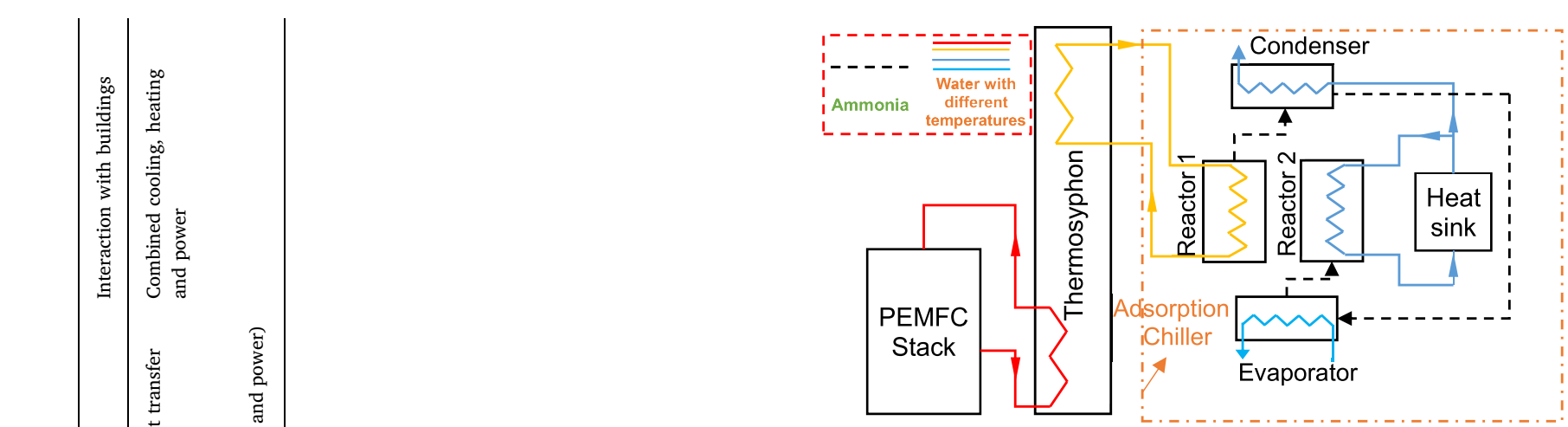

Fig. 7. Heat recovery in fuel cells with the adsorption chiller system $[119,120]$. (Note: different colors of lines indicate different temperatures.). (For interpretation of the references to color in this figure legend, the reader is referred to the Web version of this article.)

demand via the B2V interaction network. Liu et al. [132] investigated the building energy performance for different operating schedules of the CHP and different travelling schedules of EVs. Their results showed that DSM and EV scheduling can smooth the building load profile and reduce the total operational cost. Ribberink et al. [133] indicated that the generation of DHW at night for space heating via the micro-CHP will simultaneously generate a large amount of electricity, whereas the electric load of the house is low at night. The surplus electricity is not recommended to be exported to the grid due to the low feed-in tariff at night. A simulation-based study of a detached house was further conducted in Ottawa, Ontario, Canada, supported by a 2-kWe ICE-based micro-CHP system. Compared to the scenario without EV integration, by integrating EVs with buildings, the ratio of the micro-CHP power being exported to the grid can be reduced from $60 \%$ to $54 \%$, and an additional annual micro-CHP revenue of $\$ 200-\$ 300$ can be realised. Moreover, the most favourable time duration for charging the EV battery is during the peak period of the excess power of the micro-CHP.

Apart from the buildings, the grid-connected charging station can also be integrated with vehicles. According to the research results, both the solar- and the wind-supported EV charging stations can provide enough power for transportation and balance the energy of the grid $[38,48]$. The main difference between different EV charging stations with different renewable systems is the different time duration to charge the EV and to balance the energy of the electric grid. Due to the different characteristics of the renewable generation between the PV and the wind turbine, the EV charging station supported by the solar PVs produces enough electricity to charge EVs during sunny days, and it balances the demand during cloudy days. However, the load balancing period of the EV charging station supported by the wind turbine occurs whenever the load is required, especially during the period 20:00-23:00 p.m. Moreover, vehicle charging can still be realised by the traditional EV charging stations. Some of the traditional EV charging stations also have building functions, such as some associated shops, cafes, and kiosks. Therefore, there still could be some B2V and V2B functions in the traditional EV charging stations. The charging rate can be classified into three different levels, as listed in Table 7. Charging Level III is the fast charging rate, which is suitable for the public charging station. Charging Level I is suitable for the night-time home charging facility.

\subsection{Interaction between biofuel-based vehicles and buildings}

Second-generation biofuel can be produced from biomass using microbes. Currently, various types of biofuels can be produced from lignocellulosic material using microbial fermentation, such as biodiesel, bio-alcohol, and biogas [134]. Simultaneously, approaches have been proposed to enhance the efficiency of biofuel generation, such as 


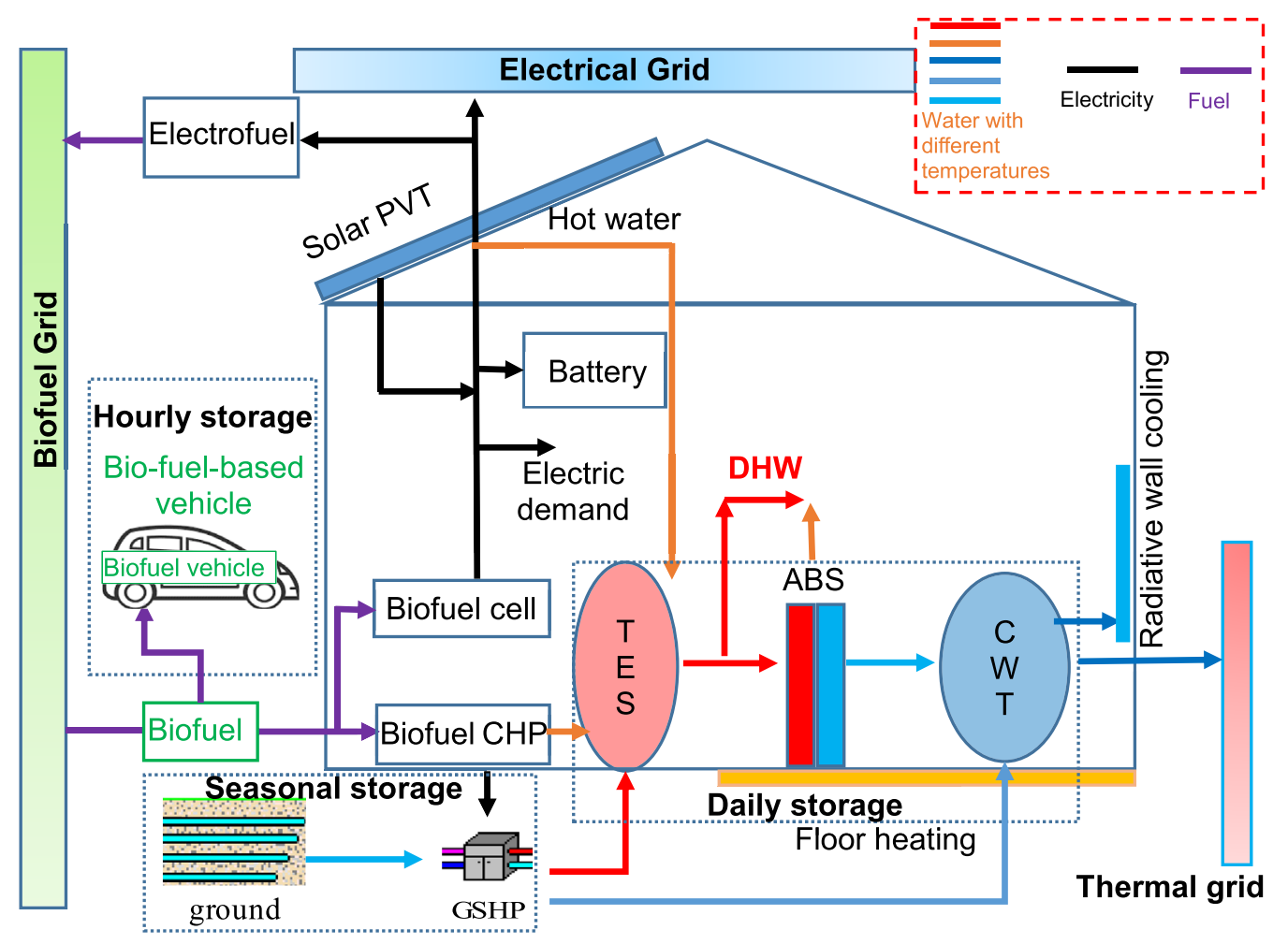

Fig. 8. Energy interaction network between biofuel-based vehicles, buildings, and hybrid grids. ABS $=$ absorption chiller, TES $=$ thermal energy storage, CWT $=$ cooling water tank, GSHP = ground source heat pump. (Note: different colors of lines indicate different temperatures.). (For interpretation of the references to color in this figure legend, the reader is referred to the Web version of this article.)

Table 7

EV charging rate.

\begin{tabular}{ll}
\hline Charging level & Typical charging power \\
\hline Level I & $1.5-3 \mathrm{~kW}$ \\
Level II & $10-20 \mathrm{~kW}$ \\
Level III & $40+\mathrm{kW}$ \\
\hline
\end{tabular}

lignocellulose utilisation, the countering lignocellulose inhibitor, biofuel tolerance, and the genetic modification of wood quality [134]. However, the interaction between biofuel-based vehicles and buildings has been rarely studied in the literature. The speedy development of biofuel generation will help promote the development of the biofuelbased vehicle. Therefore, it is worthwhile to investigate the interaction between biofuel-based vehicles and buildings. In this section, an EMS including biofuel generation, biofuel-based vehicles, and a building EMS has been formulated with respect to different energy forms, advanced energy conversions, hybrid storage systems, and hybrid grids' interactions.

The capability for the integration of biofuel-based vehicles with buildings is summarised in Fig. 9(a). As shown in the figure, several inputs are provided to the EMS, including both electrical and thermal energy from the biofuel CHP, biofuel cells, and on-site renewable energy. Moreover, the exhaust-heat-recovered energy from the biofuelbased vehicles, as mentioned in Section 4.1, will also provide both thermal and electrical energy to support the EMS. For instance, the exhaust heat in the biofuel-based vehicle can be either recovered for partially covering the DHW heating demand or recovered to generate electricity via thermoelectrical devices, the Organic Rankine Cycle, or the turbocharger system. Furthermore, both absorption and adsorption chillers can be driven by the exhaust heat to generate cooling energy, whereas the efficiency for cooling energy generation by collecting exhaust heat is dependent on the exhaust temperature. With respect to the biofuel flow in the proposed hybrid system, in addition to sending the biofuel to the biofuel CHP and the biofuel cell, it can also be sent to biofuel-based vehicles for the transportation purpose. Meanwhile, the biofuel in the vehicle can also be utilised for domestic usage via the V2B interaction as shown in Fig. 9(a). As shown in Fig. 9(b), different types of biofuels can be produced from the biomass to meet the energy demand of different biofuel-based vehicles. As shown in Fig. 9(c), the building EMS includes the metering system, centralised data acquisition system, controllers, and end users (DHW heating, air conditioning, ventilation, lighting, and devices). The input variables include renewable energy, information from the hybrid grids, the energy demand, and the scheduling of vehicles. The energy control strategy in the building EMS includes biofuel vehicle scheduling, DSM, biofuel generation, the on-site renewable system, and so on.

\subsection{Discussion on real applications and future potential}

Regarding the compatibility of building energy systems with vehicles, several technical problems need to be considered before being widely accepted in the market. Firstly, in the academia, most academic studies only presented a case study to show the potential between a single-family house and a private vehicle. The holistic overview of the energy sharing network between building clusters and vehicle fleets needs to be investigated, discussed, and promoted, in order to realise the smart city with smart energy systems. Secondly, the standardization of energy interaction facilities being installed in the B2V and V2B interaction interfaces should be developed, in order to seamlessly integrate the vehicles with building energy systems. Thirdly, due to the stochastic characteristic of occupants' behaviour, it is challenging to realise a reliable and robust energy sharing network between single buildings and vehicles, especially considering the uncertainty of the building energy demand. Therefore, the further research can be focused on the uncertainty-based study to increase the robustness and reliability of the energy sharing network. 


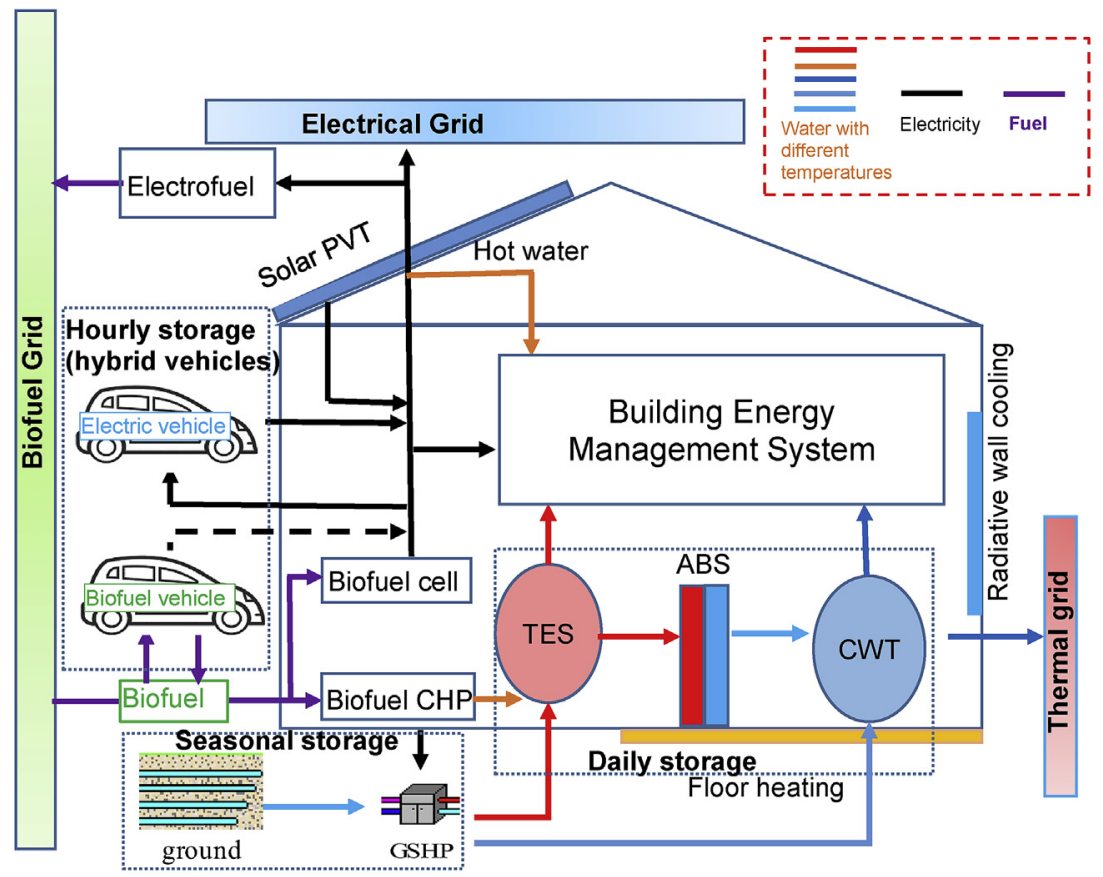

(a)

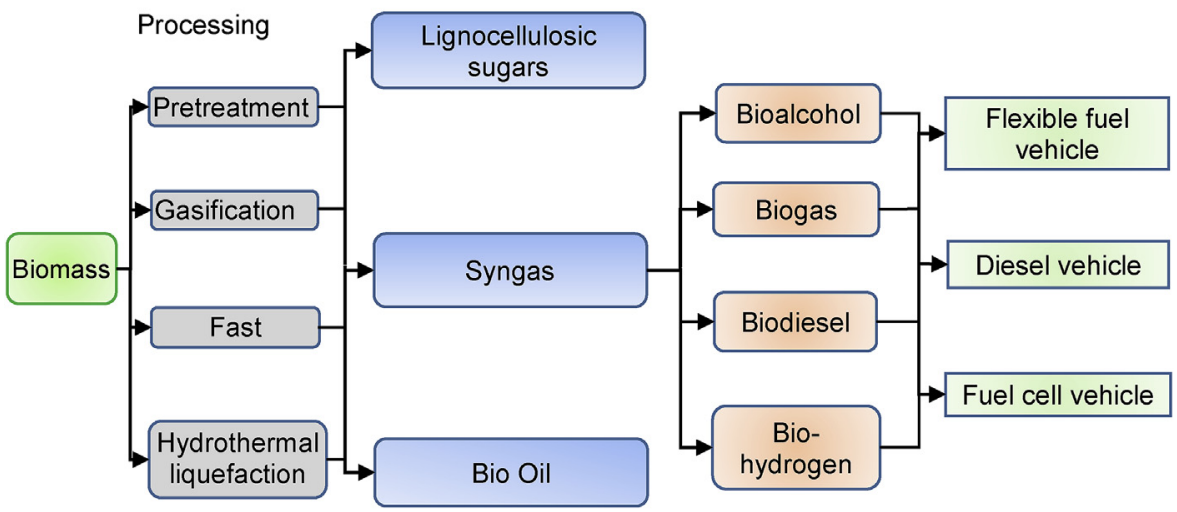

(b)

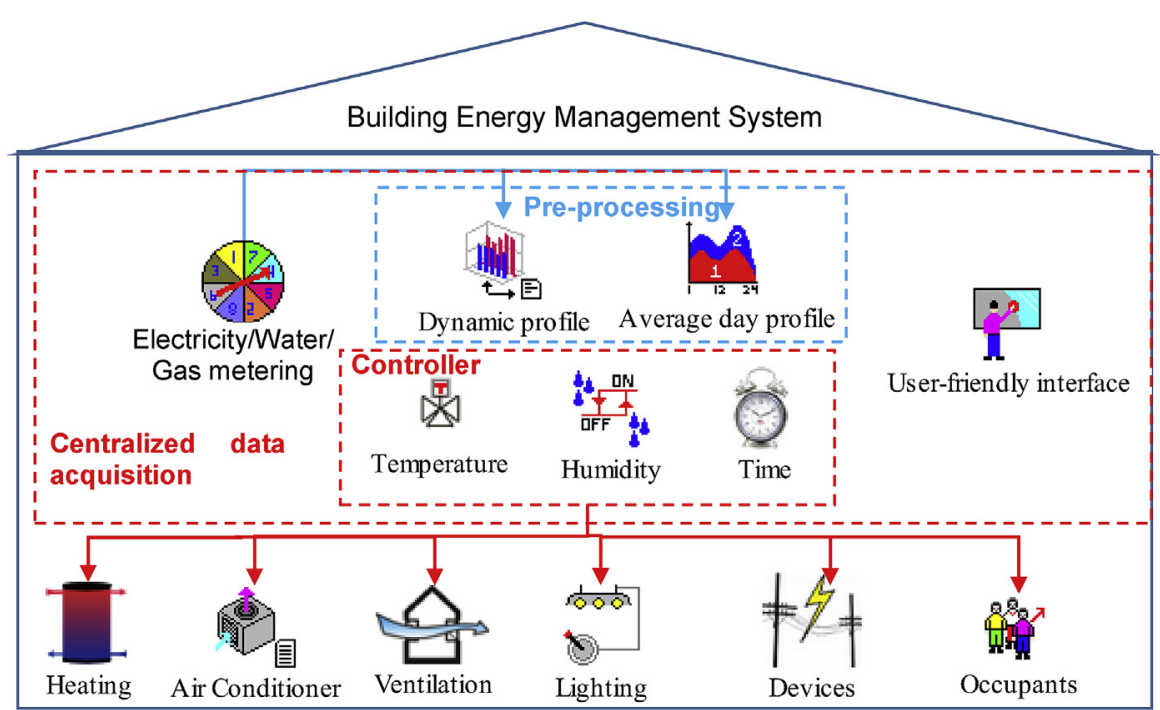

(c)

Fig. 9. (a) Configuration of the interaction between buildings, EVs, biofuel-based vehicles, and hybrid grids; (b) the biofuel generation process; (c) building energy management system (EMS). ABS $=$ absorption chiller, TES $=$ thermal energy storage, CWT $=$ cooling water tank, CHP $=$ combined heat and power, PVT $=$ photovoltaic-thermal, GSHP = ground source heat pump. (Note: different colors of lines indicate different temperatures.). (For interpretation of the references to color in this figure legend, the reader is referred to the Web version of this article.) 


\section{Current capabilities of the vehicle side for compatibility with the building}

With the rapid development of EV technology, both the V2B and the V2G interactions have attracted increasing attention from both researchers and manufacturers. The vehicle can not only serve as a mobile energy storage system, but can also serve as a source of renewable energy when being implemented with on-site PV and on-site wind turbines [53]. Currently, due to the small number of plug-in EVs, the benefit from EV integration is not very obvious in terms of the grid interaction, cost savings, and GHG emission. With the continuous and speedy increase of plug-in EVs in the upcoming epoch, the smart charging strategy is worthy of investigation in terms of levelling the load, mitigating the import/export stress on the electric grid [135], and reducing both the annual operational cost [5] and the GHG emission [28]. Therefore, it is worth investigating different smart charging strategies in the building EMS, considering the uncertainty of vehicle scheduling, energy demand, and renewable energy generation, and the power and the energy stabilisation of the hybrid grids. Moreover, with the development of EV support equipment (EVSE), long-distance EV travel can be achieved for the long-distance transportation and the elimination of the cruise anxiety from drivers. Moreover, the EVSE can be integrated with buildings to provide power for both domestic usage and transportation. For instance, the manufacturer of the Tesla produced a powerwall to charge and discharge the EV battery [136]. It is reported that the powerwall is ready to be seamlessly integrated with renewable systems and to provide the reliable power during critical periods, such as utility outages and natural disasters [136]. This section mainly reviews the capability of the vehicles for the compatibility with buildings. The energy interaction between buildings and vehicles is reviewed in this section. Meanwhile, the challenges from the vehicle viewpoint are considered in terms of realising sustainable and efficient interactions. Furthermore, discussions in the real application and future potentials have been conducted to indicate benefits from inclusion of additional work in the future.

\subsection{Electric/hydrogen vehicles}

The energy interaction between different types of buildings can be actualised by utilising the mobility of vehicles' storages, forming the interactive energy sharing network. The interactive energy sharing network is dependent on several impact factors, such as the uncertainty of renewable generation, building demand profile, travelling schedule of the vehicles, involved energy forms, and capacity of the storage system in the vehicles. For example, with respect to a work-based EV as shown in Fig. 10, during the daytime, the EV can shave the peak renewable power of the office building by charging the battery and cover the valley demand power of the residential building by discharging the battery system. When the residential building is supported by a microwind turbine, the EV can be charged during the night-time and be discharged to cover the energy demand in the office building during the daytime. However, some technical problems and challenges need further consideration before being widely accepted in the market. First, from the perspective of the cost, if there is no official legislation related to both the initial and the operational cost of the renewable system, the investors will be unmotivated due to the cost from the installation of renewable systems in office/residential buildings. A possible solution could lie in selling the renewable energy to end users with the vehicles' integration. Moreover, in Hong Kong, to promote the utilisation of renewable energy, the Hong Kong government and the administrator have proposed a specific grid feed-in tariff scheme [137], which has fixed the export cost at $3-5$ times the price of the import cost. This grid feed-in tariff of the on-site renewable energy will greatly encourage investors to install the renewable system. Therefore, it is necessary to integrate a larger scale of vehicles with buildings to match the larger scale of the renewable system. Second, the degradation of the EV battery will make the drivers unwilling to store renewable electricity in EVs if there are no subsidies for the depreciation of the EV battery. Third, considering the characteristics of the energy demand profiles in both residential and office buildings, different on-site renewable systems are recommended in different buildings. For instance, from the perspective of the energy interaction between work-based vehicles and buildings, the wind turbine is recommended in residential buildings for night-time interaction, and PVs are recommended in office buildings for daytime interaction.

It should be noted that renewable sources can not only be installed in buildings, but also be installed on vehicles to increase both the cruising range and the travelling speed. The integration of a mobile renewable system with the EV has been investigated by Fathabadi [53]. From their results, during a sunny day, compared to a plug-in hybrid EV without any mobile renewable system, the daily cruising range of a plug-in hybrid EV is extended by $19.6 \mathrm{~km}$ with the implementation of a

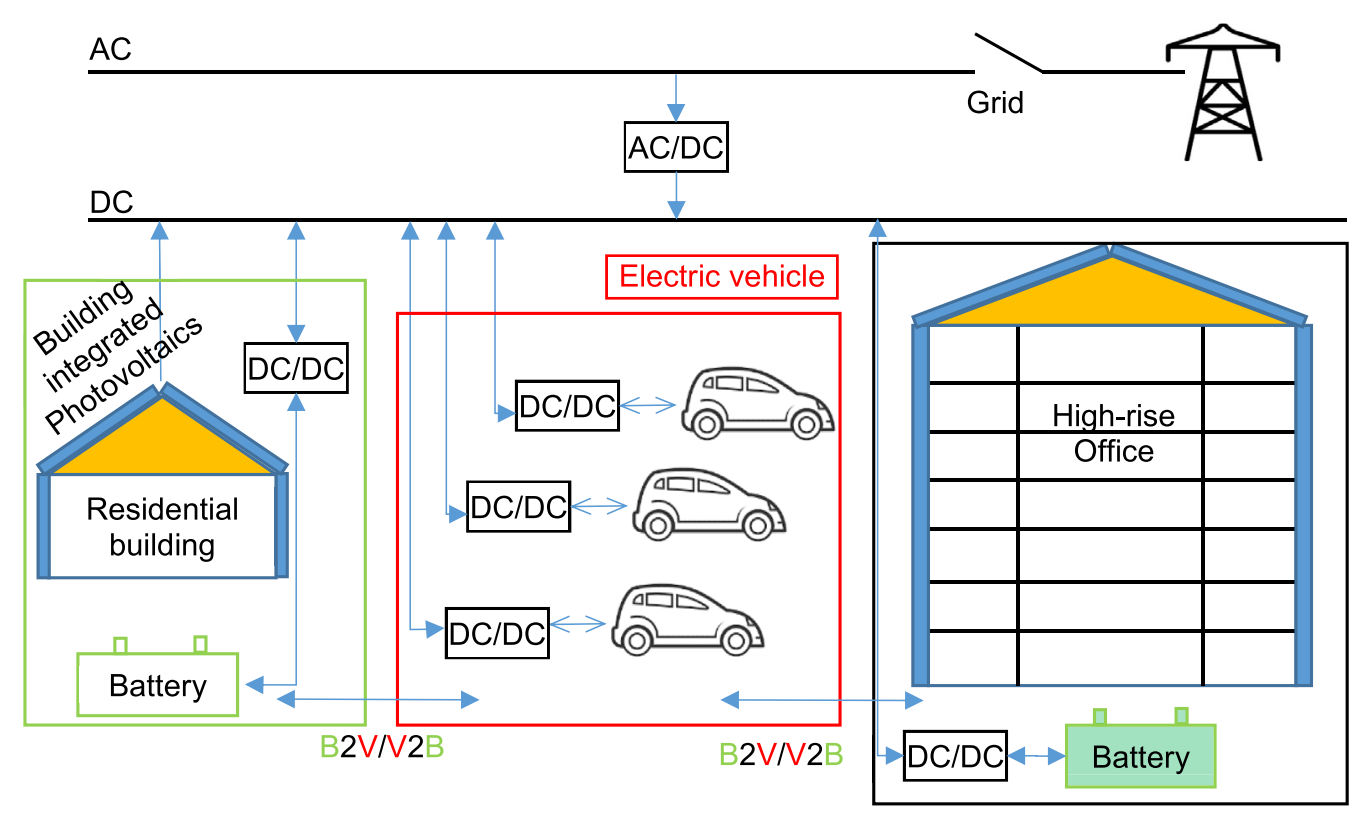

Fig. 10. An axample of the energy interaction between residential buildings and high-rise office buildings via electric vehicle fleets. 
mobile PV/wind system. Meanwhile, compared to a plug-in hybrid EV without any mobile renewable system, the hybrid PV/wind renewable system can provide a higher power efficiency of $91.2 \%$ and a higher speed of $121 \mathrm{~km} / \mathrm{h}$. Mobile renewable systems on vehicles have also attracted increasing attention from several companies such as Toyota [68]. However, in the academic literature, the mobile renewable systems on the EV is only utilised to extend the cruising range and the speed of the vehicle, whereas the interaction with the building load has been rarely considered. In future, with the development of wireless EV charging as shown in Ref. [138], when the EV cruising range will not be a concern, it will be worthwhile to investigate the impact of mobile renewable sources on the V2B energy interaction and the hybrid grids' interactions. Moreover, with the application of the mobile renewable system, more renewable energy can be made available for both transportation and domestic usage. Therefore, the energy demand for transportation will be less dependent on the vehicles' scheduling and the demand-side control strategy. In addition, in order to promote costeffective energy storage systems [139] and reduce the capital cost of lithium-ion batteries [140] in the building EMS, the utilisation of retired EV batteries for second-use applications is promising through sophisticated recycling, re-manufacturing, and reusing processes. It has been concluded that the estimated profit rate can reach approximately $35 \%$ in 15 service years with the application of a 10-kWh Li-ion battery [140]. Cusenza et al. [141] investigated the load matching and environmental sustainability by recycling the retired electric vehicle batteries in buildings. According to their results, the further development of advanced technologies is highly desirable to obtain better performances, although the integration of retired battery storage systems allows the improvement of the environmental sustainability of the electricity supply in a residential building.

The current capability of the vehicle side for compatibility with the building has also been considered by several manufacturers. Table 8 lists the parameters of several EVs for B2V and/or V2B interactions. As listed in Table 8 , the B2V charging rate is set to be $6.6 \mathrm{~kW}$ for some EVs, such as the 2018 Fusion Energi SE, 2018 Focus Electric, and 2018 Nissan LEAF. Manufacturers also focused on the development of vehicles for domestic usage, such as the Nissan LEAF [142]. From the technical perspective, by installing a power control system connected to the household's distribution board, household power can be supported by a Nissan LEAF lithium-ion battery [143]. The building energy demand can be shifted via the operation of charging and discharging of the EV battery according to both the renewable generation and the building energy demand. Furthermore, during emergency periods, the $\mathrm{B} 2 \mathrm{~V}$ and/or V2B interaction can provide reliable energy for domestic usage. According to the product information released by the manufacturer [136], a powerwall is integrated with the renewable system to store excess renewable energy during sunny days. The powerwall will provide electricity for domestic usage whenever excess energy is required, and thus minimise the reliance on the electric grid. From the technical perspective, the powerwall can provide an electrical energy of $13.5 \mathrm{kWh}$ with a peak power of $7 \mathrm{~kW}$.

Table 9 lists the parameters of several HV products in the vehicle market. In the HV industry, some vehicle manufacturers have already considered thermal and electrical conversions and hybrid storage between HVs and buildings [144,145]. For instance, to back up the building load, the manufacturer of the Toyota Mirai claims that it can provide a total electrical energy of $60 \mathrm{kWh}$ with a peak power of $9 \mathrm{~kW}$. As the daily energy consumption of a residential building is estimated to be $12 \mathrm{kWh}$ in Japan [147], the Toyota Mirai can completely support the energy consumption of a residential building for 5 days.

\subsection{Biofuel-based vehicles}

Two technical approaches for biofuel generation are popular, including thermochemical and biochemical processes [134,151]. The most advanced fourth-generation biofuels are created by using either petroleum-like hydro-processing or advanced biochemistry and revolutionary processes such as the solar-to-fuel method [152]. Moreover, it is possible to capture $\mathrm{CO}_{2}$ for the generation of fourth-generation biofuels, although several technical barriers need to be overcome before being widely accepted in the market [153,154].

Biofuel-based vehicles can be classified into three types according to the biofuels in the vehicles: flexible fuel vehicles, diesel vehicles, and fuel-cell vehicles [117]. Biofuels for supporting these three vehicles are listed in Table 6 in Section 4.2. In the literature, there are a lot of studies on the adoption of exhaust heat recovery technology to meet both the thermal and the electrical demands of the vehicles [155-157]. However, a few studies focus on the interaction between biofuel-based vehicles and buildings. The impact of the energy interaction between gasoline-based vehicles and buildings on the energy demand for both buildings and transportation has also been rarely studied. In this section, an energy interaction network from the vehicle side has been formulated to realise the energy interaction with respect to different energy forms, advanced energy conversions, and hybrid energy storage systems. Meanwhile, challenges for realising sustainable and efficient interactions can have been demonstrated as avenues for future research.

In the academic world, the ICE-based CHP and the mCHP are widely used for building energy applications. For instance, Talom et al. [155] indicated that the exhaust gas from a 2.8-L internal combustion engine in the Mercedes V6 can be used to drive a 10.55-kW absorption chiller and to partially cover the cooling load of buildings. This technical solution is promising in cooling-dominated regions. Another application for the exhaust heat recovery technology of ICEs is to preheat the supply air in the heating-dominated region. Alanne et al. [158] recovered the exhaust thermal energy in the ICE to preheat the supply air. Their results indicated that, in comparison with a conventional hydronic heating system, a $3-5 \%$ decrease in the primary energy consumption and $\mathrm{CO}_{2}$ emissions will be actualised with the adoption of the heat recovery technology. It should be noted that these studies are based on the ICE-based CHP or mCHP for building energy applications. However, studies on the use of the vehicle ICE for building applications are limited. In this section, an energy interaction network from the vehicle side has been formulated to realise the energy interaction

Table 8

Technical parameters of several electric vehicles (EVs) available in the market.

\begin{tabular}{|c|c|c|c|c|c|c|}
\hline Company & Renewable system & Vehicle model & Battery technology & Battery size & $\begin{array}{l}\text { Home charging } \\
\text { rate }\end{array}$ & Energy/energy interaction \\
\hline Ford & & $\begin{array}{l}2018 \text { FUSION ENERGI SE; } 2018 \text { FOCUS } \\
\text { ELECTRIC }\end{array}$ & Li-ion & $35 \mathrm{kWh}$ & $6.6 \mathrm{~kW}$ & \\
\hline Toyota & Solar panel roof [68] & Prius, Lexus & $\mathrm{NiMH}$; Li-ion & & & \\
\hline BMW & & 2017 BMW i3 & Li-ion & $33 \mathrm{kWh}$ & & \\
\hline BYD & & E6 & Li-ion & $61 \mathrm{kWh}$ & & \\
\hline Nissan & & 2018 NISSAN LEAF & Li-ion & $30 \mathrm{kWh}$ & $6.6 \mathrm{~kW}$ & $6 \mathrm{~kW}[142]$ \\
\hline Tesla & Powerwall [136] & Model S, Model X, Model 3, Roadster & Li-ion & $100 \mathrm{kWh}$ & & $\begin{array}{l}13.5 \mathrm{kWh}[136](7 \mathrm{~kW} \text { peak } / 5 \mathrm{~kW} \\
\text { continuous) }\end{array}$ \\
\hline
\end{tabular}


Table 9

Battery types and parameters of several HVs available in the market.

\begin{tabular}{|c|c|c|c|c|}
\hline Company & Vehicle model & Battery & Hydrogen tank mass/volume & Energy/energy interaction during the emergency period \\
\hline Toyota & Mirai & 1.6 kWh NiMH; Li-ion & $87.5 \mathrm{~kg}(70 \mathrm{Mpa})[144]$ & $60 \mathrm{kWh}$ (peak power: $9 \mathrm{~kW}$ ) [144] \\
\hline Mercedes & Mercedes-Benz F-Cell & 13.8 kWh Li-ion [145] & $4.4 \mathrm{~kg}(700 \mathrm{Bar})[145]$ & \\
\hline Honda & Clarity Fuel Cell & 11.6 kWh Lithium-ion Battery [146] & $3.5 \mathrm{~L}[148]$ & \\
\hline Nissan & Solid-Oxide Fuel Cell vehicle [149] & 24 kWh Li-ion battery $[150]$ & 30-L tank capacity $[150]$ & SOFC output power: $5 \mathrm{~kW}$ [150] \\
\hline
\end{tabular}

between biofuel-based vehicles and buildings as shown in Fig. 11 .

Fig. 11 shows the energy interaction network between biofuel-based vehicles, buildings, and hybrid grids from the vehicle side. There are two energy recovery technologies in the energy interaction network: the exhaust heat recovery technology from the ICE and the brake energy recovery technology. With respect to the exhaust heat recovery, both thermal and electrical energy can be generated depending on the adopted technologies, such as thermoelectrical devices, the Organic Rankine Cycle, and the turbocharger, as listed in Table 5, Section 4.1. Power can be generated by converting the pressure from on-road vehicles using the piezoelectric pressure transducer. Readers are recommended to refer to Reference [159] for more detailed information. From their results, the lighting load of the university under study could be covered by increasing the number of vehicles passing through the road. Islam et al. [160] noted that by increasing both the capacity of the generator and the weight of the vehicles, the efficiency of the whole system can be increased further. In addition to pressure power generation, electricity can also be generated from the biofuel cell, the internal combustion engine, and even the mobile renewable system in vehicles. Several options are available to manage the on-site surplus electricity: 1) the energy demand of lighting, the HVAC and transportation of vehicles; 2) building demand through the V2B interaction; 3) electrofuel generations [131]. The electrofuels can be generated by using bacteria to produce biofuel from renewable energy and $\mathrm{CO}_{2}$ or by employing self-reliant microorganisms that can directly use the energy from electricity and chemical compounds to produce liquid fuels [131]. For the biofuel-based CHP or the mCHP for building energy applications, biofuel can also be imported from the biofuel grid to drive the CHP.

On the basis of our formulated energy interaction network, several challenges need to be considered before the system can be widely accepted in both academia and market. First, from the perspective of the cost, drivers are reluctant to install the mobile renewable system in their vehicles if the export cost of both the electricity and the electrofuels is much lower than the installation and operational costs. Second, the degradation of the biofuel cell and ICEs in the vehicles will make drivers unwilling to integrate their vehicles with buildings if there is insufficient subsidy for the depreciation of the biofuel cell and the ICEs. An appropriate policy needs to be legislated, comprehensively involving vehicle owners, the department of energy, and occupants, in terms of promoting the energy interaction between biofuel-based vehicles, buildings, and hybrid grids.

\subsection{Discussion on real applications and future potential}

Regarding the compatibility of vehicles' energy systems with building energy systems, several technical problems need to be considered in the academia. Firstly, depending on different fuels, sizes and capacities in the power supply system, vehicles in the market are diversified, making it rather difficult to be seamlessly integrated with

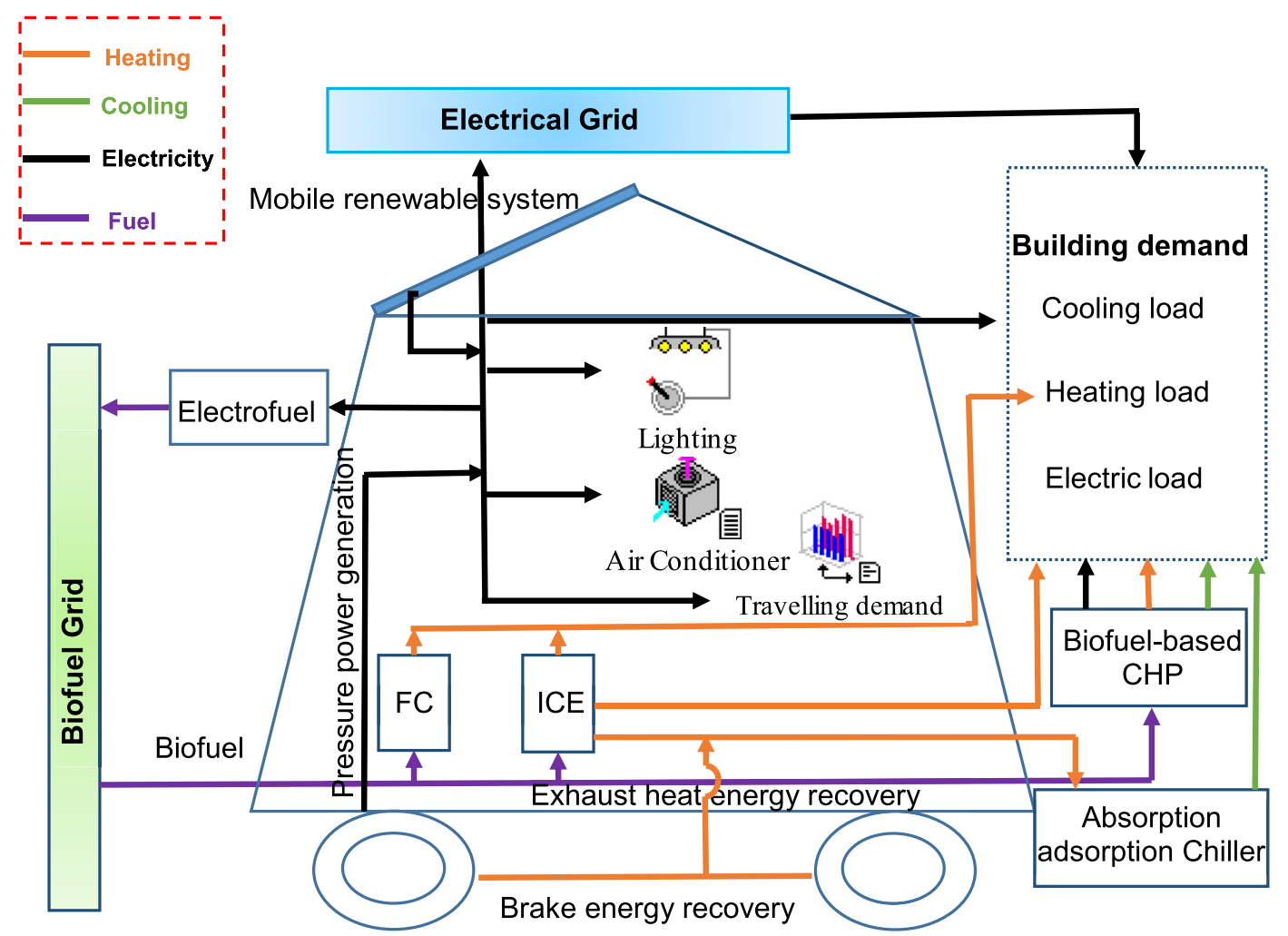

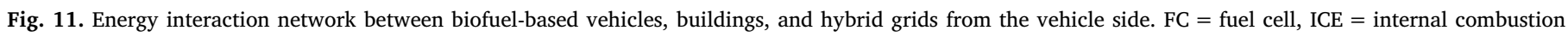
engine, $\mathrm{CHP}=$ combined heat and power. 
building energy systems and to provide reliable power during critical periods. For instance, it is rather difficult to integrate different vehicle fleets with public buildings due to the difference in cables and piping systems. The development of standardized charging/discharging cables and piping systems, according to the characteristics of integrated vehicles, is essential for the real applications. Secondly, due to the stochastic characteristic of vehicles, it is challenging to realise a reliable and robust energy sharing network between single buildings and vehicles, especially considering the massive vehicles' flow and the uncertainty of time durations for the energy interaction. Therefore, further research can be focused on the development of the optimal system design and the optimal control to increase the robustness and reliability of the energy sharing network.

\section{Future trends of energy interactions between buildings and vehicles}

\subsection{Thermal-electricity-electrofuel interaction}

Technical solutions for diversified energy interactions between buildings and vehicles have been rarely investigated. As listed in Table 5, Section 4.1, there are three technologies for recovering waste heat to generate electricity, including thermoelectrical devices [15], the Organic Rankine Cycle [16], and the turbocharger system [17]. Before being widely accepted by manufacturers, several technical problems need to be addressed in terms of the electricity generation from the exhaust heat in ICE vehicles. In regard to thermoelectrical devices, the low efficiency of power generation (typically $\eta_{\mathrm{th}}<4 \%$ [99]) is the main barrier for the wide application of the thermoelectric generator (TEG) device. Other challenges for the TEG include the increased size of the radiator and the extended length of the exhaust gas pipes. The nanofluid is thus investigated and validated to be promising in terms of addressing this issue when being integrated with the thermoelectric generation system $[115,161]$. With respect to the turbocharger system, the turbo lag during low-speed acceleration affects the drivability and performance of the engine. At the current stage, there is no promising solution or idea for this technical issue.

In regard to the biofuel-based vehicle, the biofuel can be converted into electricity using the biofuel cell. In comparison with the traditional fuel cell, the biofuel cell does not involve combustion during the reaction process, and thus the energy conversion is not restricted by the circulation of Kano. Moreover, the biofuel cell has remarkable characteristics of high efficiency and cleanliness. With these promising potentials, the biofuel cell is regarded as the "fourth power generation mode" following the three types of power generation methods: hydraulic, thermal, and atomic energy. Moreover, fuel sources are widespread, such as ethanol, glucose, organic/inorganic/microbial metabolites, fermented products, photosynthesis, and even sewage. The exhaust heat from the biofuel-based vehicle can also be converted to electricity. When there is surplus electricity, it can be converted to electrofuel, which can be either sold to the biofuel grid or be used to cover the energy demand for the transportation of the fuel-based vehicle. The electrofuel generation process consists of the application of microorganisms, especially bacteria, to directly generate biofuels from electricity. Electrofuels are emerging types of carbon-neutral drop-in replacement fuels that are made by storing electricity from renewable sources in the chemical bonds of liquid or gas fuels [162,163]. The primary targets are butanol, biodiesel, and hydrogen, together with other alcohols and carbon-containing gases such as methane and butane. Energy integrations and interactions between biofuel-based vehicles and buildings are gradually accepted in the market, especially with the further improvement of conversion efficiency from electricity to electrofuels.

\subsection{Network for interactions between biofuel-based vehicles, EVs, and buildings}

In this section, the energy interaction network, including biofuel-

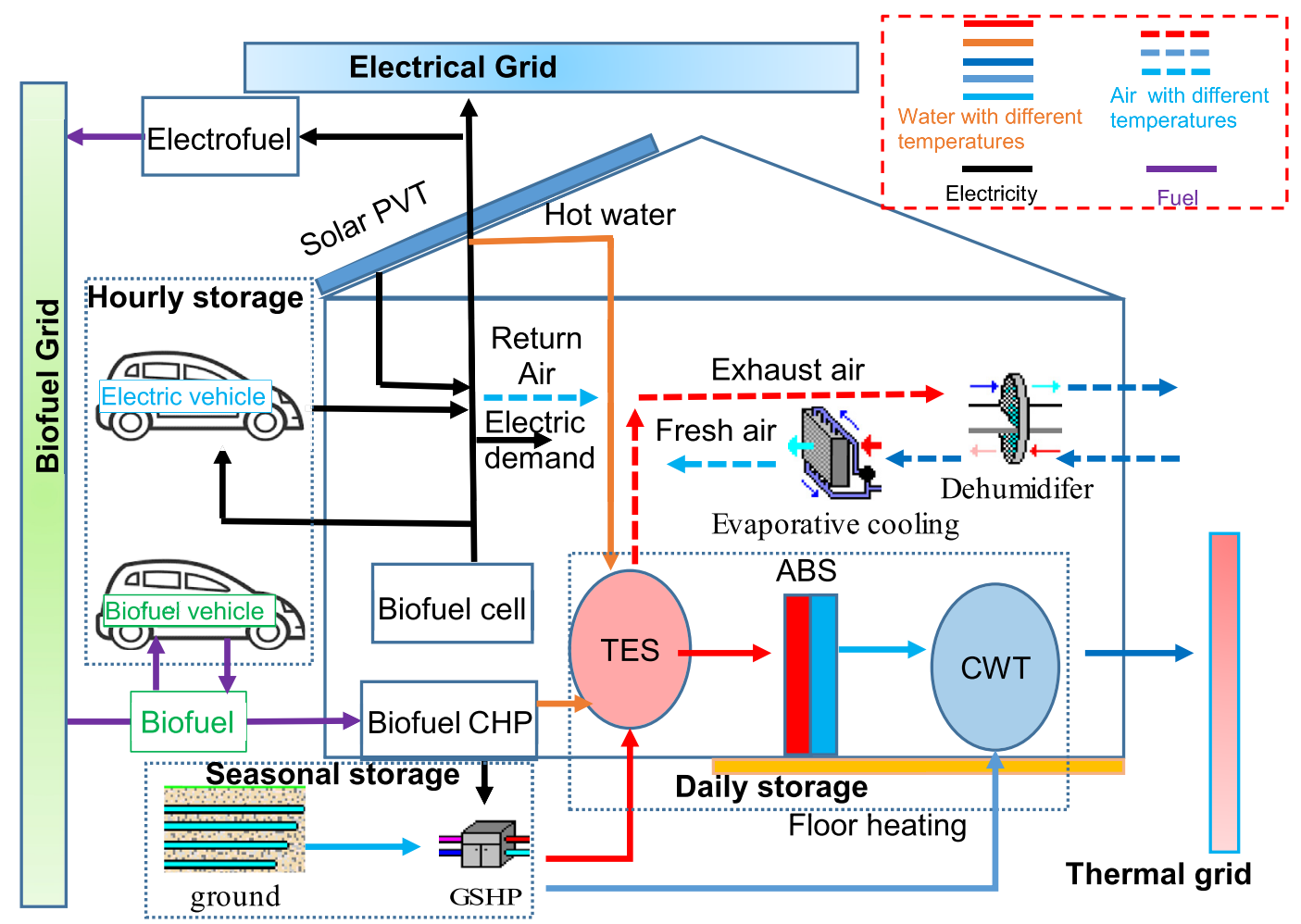

Fig. 12. Energy interaction network between biofuel-based vehicles, electric vehicles (EVs), and buildings. ABS $=$ absorption chiller, TES $=$ thermal energy storage, CWT $=$ cooling water tank, PVT $=$ photovoltaic-thermal, GSHP $=$ ground source heat pump, CHP $=$ combined heat and power. (Note: different colors of lines indicate different temperatures.). (For interpretation of the references to color in this figure legend, the reader is referred to the Web version of this article.) 
based vehicles, EVs, and buildings, is constructed with different energy forms, advanced energy conversions, hybrid energy storage systems, and hybrid grids' interactions. As shown in Fig. 12, biofuels imported from the biofuel grid can be used for transportation (biofuel vehicles) and buildings (the biofuel-based CHP and biofuel cells). The electricity generation source also includes the solar PV/T system. The generated electricity can be used for charging the EV for hourly storage. The surplus electricity can also be converted into electrofuel. Electrofuels are generated by using bacteria to produce biofuel from renewable energy and $\mathrm{CO}_{2}$, or by using self-reliant microorganisms that can directly use the energy from electricity and chemical compounds to produce liquid fuels [131]. In order to cover the heating demand of buildings, hot water from the PV/T system, the biofuel CHP, and the GSHP systems will be stored in the TES tank. Both the TES tank and the CWT are designed for the daily storage purpose. Seasonal storage, such as the ground, is charged and discharged by the GSHP to maintain the energy balance between the total energy released into and the total energy absorbed from the ground. In the cooling-dominated region, the implementation of the absorption or the adsorption cooling system can convert heating energy to cooling energy. Moreover, the evaporative cooling system can also facilitate the energy balance as the thermal energy can be used to heat the exhaust air and to dehumidify the outdoor fresh air. However, to realise this energy interaction network, the most challenging issue is that, in order to drive both the absorption or the adsorption cooling systems and the evaporative cooling system, the heat source should be at a higher temperature than $80^{\circ} \mathrm{C}$ [164], which is much higher than the condenser temperature of the GSHP: $60-70^{\circ} \mathrm{C}$. Additional thermal energy is required to active the cooling systems.

\subsection{Network for interactions between HVs, EVs, and buildings}

Fig. 13 demonstrates the energy interaction network between EVs, HVs, and buildings. Hydrogen imported from the hydrogen grid can be used for transportation (HVs) and buildings (the fuel cell). In addition to the electricity generation from the fuel cell, the solar PV/T system can generate electricity for domestic usage. In order to cover the heating demand of the building, hot water (from the GSHP and the PV/ $\mathrm{T}$ system) and the cogenerated hot water (from the fuel cell) will be stored in the TES tank. With respect to the end users, the radiative cooling wall and the under-floor heating system are designed to guarantee the indoor thermal comfort.

\subsection{Challenges and outlook for future trends}

In both the academic and industrial worlds, the integration of EVs is recognised as a more technical competitive technique in term of sharing electricity with buildings than either ICE-based or hydrogen-based vehicles. For instance, according to Ref. [12], due to the lower efficiency of the HV system compared to the EV system, the HV integrated building energy system will be more demanding in meeting the energy balance than EV integrated building energy system. However, to make the EVs' integration with building energy system more technical competitive and acceptable, several technical challenges that need further consideration are summarised below.

\section{1) Necessity and distribution of EV charging infrastructure}

Currently, due to the inconvenience and the unavailability of charging facilities, several researchers have noticed the cruise anxiety associated with pure battery-based EVs due to their limited storage capacity. Moreover, the discharging of the EV battery when being integrated with buildings will aggravate this cruise anxiety. Therefore, increasing the total number of EV charging stations with an optimised spatial distribution is essential for an effective energy sharing network. Furthermore, due to the varying characteristics of renewable energy generation, different renewable systems are recommended to be implemented together for energy compensation from the temporal aspect. As listed in Table 10, a renewable source that can generate renewable energy during the entire night, such as a wind turbine, is recommended to be installed in residential charging stations. Likewise, a renewable source that can generate centralised electricity, such as solar PVs, will

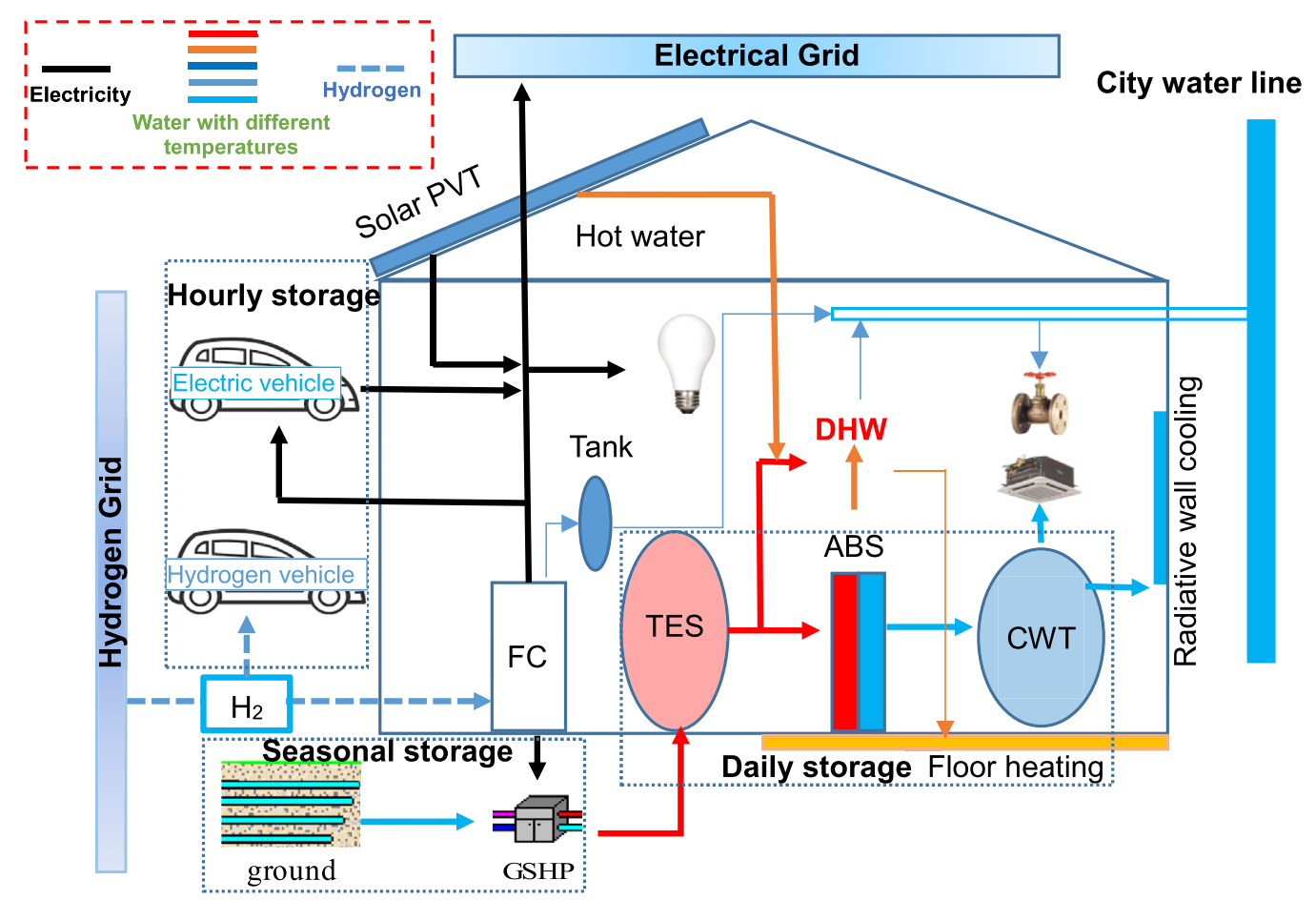

Fig. 13. Energy interaction network between hydrogen vehicles (HVs), electric vehicles (EVs), and buildings. ABS = absorption chiller, TES $=$ thermal energy storage, CWT $=$ cooling water tank, PVT $=$ photovoltaic-thermal, GSHP $=$ ground source heat pump, CHP $=$ combined heat and power. (Note: different colors of lines indicate different temperatures.). (For interpretation of the references to color in this figure legend, the reader is referred to the Web version of this article.) 
Table 10

EV charging infrastructure and their integrations with buildings.

\begin{tabular}{|c|c|c|c|}
\hline EV charging infrastructure & Preferable renewable sources & Energy integrations & Comments \\
\hline $\begin{array}{l}\text { Residential charging station } \\
\quad \text { (Slow charging) }\end{array}$ & $\begin{array}{l}\text { Renewable source with renewable } \\
\text { generation overnight, like wind turbine }\end{array}$ & $\begin{array}{l}\text { Charging the EV at the valley period and the EV } \\
\text { being discharged at the peak period }\end{array}$ & $\begin{array}{l}\text { Typically associated with the overnight } \\
\text { charging }\end{array}$ \\
\hline $\begin{array}{l}\text { Public charging station (Fast } \\
\text { charging) }\end{array}$ & $\begin{array}{l}\text { Renewable source that can generate } \\
\text { centralised electricity }\end{array}$ & $\begin{array}{l}\text { EV acting as the energy carrier to carry the power in } \\
\text { the public charging station for the domestic usage }\end{array}$ & $\begin{array}{l}\text { Power charging rate higher than } 40 \mathrm{~kW} \text {, } \\
\text { delivering over } 100 \mathrm{~km} \text { between } 10 \text { and } 30 \mathrm{~min}\end{array}$ \\
\hline Wireless power transfer (WPT) & & $\begin{array}{l}\text { The WPT for the domestic usage via the EV when } \\
\text { the WPT charging cost is low }\end{array}$ & $\begin{array}{l}\text { The power transmitted through transmitter } \\
\text { unit on EVs without any physical contact }\end{array}$ \\
\hline
\end{tabular}

be suitable in public fast charging stations.

2) Challenges for buildings and electric grid in the G2V/B2V interaction

When integrating EVs with buildings, both the buildings and the electric grid will face several challenges resulting from the mismatch between the renewable generation and the energy demand, the increased electrical demand, the limited storage capacity of the EV, and so on. The specific challenges for the energy interaction in the G2V/B2V interaction are listed in Table 11.

3) Opportunities for energy interactions between buildings and vehicles

There are several opportunities deriving from addressing the abovementioned challenges. First, by strategically installing and managing the charging stations, the EVs can be an important source of flexibility for the energy balance $[165,166]$, helping to prevent price spikes of electricity and to avoid the further upgrades of the grid capacity. For instance, Tao et al. [7] optimised the layout of the battery-based EV charging infrastructure using real-world driving data. Their results show that compared to the current layout of the charging infrastructure, the over-discharging rate of the EVs can be reduced from $68.1 \%$ to $39.6 \%$ through the optimisation of the layout of EV charging infrastructures.

Moreover, the vehicle generates on-site renewable energy when renewable systems are installed in the vehicles. On-site renewable generation in the vehicle has several advantages. First, integrating a renewable system with the vehicles will be one of the effective solutions in terms of reducing the cruise anxiety of drivers. Fathabadi [53] indicated that when the EV is implemented with renewable systems supported by both solar energy and wind energy, the cruising range of a plug-in hybrid EV (PHEV) will be extended by $19.6 \mathrm{~km}$ on a sunny day. Moreover, compared to the normal operation of the PHEV, the renewable-supported EV can provide a higher power efficiency of $91.2 \%$ and a higher speed of $121 \mathrm{~km} / \mathrm{h}$. Second, when mobile micro-wind turbines are installed in the vehicles, the kinetic energy can be converted to renewable energy for the transportation use. Third, as the energy demand for transportation can be partially covered by the onsite renewable system, the expansion requirement of grid capacity will be mitigated. Furthermore, compared to traditional vehicles without any renewable systems, the vehicle with the on-site renewable system has more chances to become a NZEV due to the increase of the selfconsumed renewable energy.

\section{Conclusions}

In this study, a holistic overview of hybrid energy interaction networks has been presented. A systematic analysis has been provided regarding the energy integration and interaction between buildings and vehicles with respect to different energy forms, advanced energy conversions, diversified energy storage systems, and hybrid grids' interactions. The reviewed buildings include residential buildings, public buildings, transportation buildings, and biofuel generation factories.
The reviewed vehicles include conventional gasoline-based vehicles, biofuel-based vehicles, battery-based vehicles, and fuel-cell electric vehicles. A systematic review of commercial products of both batterybased vehicles and fuel-cell-based vehicles was presented from the standpoint of different vehicle models, battery sizes, hydrogen tank volumes, and home charging/discharging rates. The investigated hybrid grids include the biofuel grid, hydrogen grid, district thermal grid, and electrical grid. The role of the electric grid in the hybrid energy network was reviewed, and the assessment criteria were demonstrated from the perspectives of energy consumption, operational cost, and $\mathrm{CO}_{2}$ emission. A systematic and comprehensive energy interaction network was thereafter formulated for the first time in this study to bridge the scientific gaps. Technical solutions for the energy interaction enhancement were systematically presented and discussed from the standpoint of buildings (such as on-site PVs, on-site wind turbines, biofuels, and geothermal energy) and vehicles (mobile storages and mobile renewable systems). In addition, an interactive energy sharing blueprint involving different energy sharing networks was formulated on the basis of the mobility characteristics of vehicle fleets. Afterwards, technical challenges have been proposed together with future potentials, that need further investigation. From our study, several conclusions can be drawn:

1) In the academic world, challenges for buildings and vehicles interaction networks mainly include the stochastic characteristic of the vehicles, the occupant-dependent building load, the uncertainty of the renewable generation, the accurate sizing methodology of the renewable system, the prediction of the lifetime, and the fault diagnosis of the EV battery. Performance assessment criteria for the buildings and vehicles interaction network include the grid interaction, the annual matching capability, the annual net equivalent $\mathrm{CO}_{2}$ emission, and the annual net operational cost.

2) The energy interaction networks between buildings, vehicles, and the electric grid have been demonstrated, and the main function of the electric grid is to instantaneously balance the energy of the vehicles' integrated energy network. In some regions such as islands, the vehicles can support and stabilise the local weak electric grid. Furthermore, the buildings can provide flexibility to the electric grid through the demand side management, the load control and the grid response.

3) Advanced energy storage systems (including active storage systems, such as battery and thermal storage tanks, and passive energy storage systems, such as the thermal mass of the building envelope) are effective solutions in terms of reducing the rated capacity of building devices and enhancing the matching capability of the vehicles' integrated energy network. Unlike the performance of active storage systems, the performance of passive storage systems was mainly dependent on the insulation and the emitter. Technical solutions can be proposed for active storage systems, such as the excess renewable-recharging strategy, to fully utilise the storage capacity, reduce the grid interaction, and improve the matching capability.

4) In the academic literature, technical solutions for recovering the exhaust heat in gasoline-based vehicles for building usage include thermoelectrical devices, the Organic Rankine Cycle, and 
turbocharger systems. The main challenges can be summarised as the low heat recovery efficiency and the depreciation of biofuel cells and internal combustion engines.

5) A systematic and comprehensive energy interaction network has been formulated for the first time involving different energy forms, advanced energy conversions, hybrid energy storage systems, and hybrid grids' interactions (the biofuel grid, hydrogen grid, electric grid, and thermal grid). Challenges for hybrid energy networks include grid capacity expansions, frequent grid power fluctuations, static export costs, unpredictable schedule of vehicles, synchronized peak load of buildings and vehicles, together with the availability of charging facilities and fuel stations. In order to promote interactive energy sharing networks in the smart energy system, technical solutions need to be further investigated, including the installation of mobile renewable systems, vehicle scheduling optimisation, layout optimisation of vehicle charging stations or fuel stations, and policy incentives from policymakers.

Through a systematic literature review and the in-depth discussion on the energy integration and interaction between buildings and vehicles, the realisation of a renewable and sustainable energy sharing network is promising for clean power production and the climate change mitigation. Both the building energy system and the transportation can interact with each other through energy interactive mechanisms such as those formulated in this paper. By realising a systematic interaction of different energy sharing networks via the mobility of vehicle storages, the energy systems can become more robust, reliable and flexible. However, more efforts are needed on many aspects. Incentives and subsidies should be provided to vehicle owners for the depreciation of their vehicles when participating in renewable and sustainable energy sharing networks. Social acceptance of the security of high-pressure hydrogen storage tanks need more attention when integrating buildings with hydrogen vehicles. Regarding the exhaust heat recovery from vehicles, the implementation of advanced thermo-electrical materials would be very useful to enhance the heat recovery efficiency. Furthermore, the standardization of interactive facilities, such as electric charging/discharging cables and hydronic thermal networks, needs to be further developed for facilitating the design and operations of the energy interactions between different types of buildings and vehicles.

\section{Acknowledgement}

This work is supported by the Hong KongRGC (Research Grants Council) Research Project 25215618.

\section{References}

[1] HKEED (Hong Kong Energy End-use Data). Hong Kong energy end-use data 2018. https://www.emsd.gov.hk/filemanager/en/content 762/HKEEUD2018.pdf; 2018.

[2] Tie SF, Tan CW. A review of energy sources and energy management system in electric vehicles. Renew Sustain Energy Rev 2013;20(4):82-102.

[3] Thomas D, Deblecker O, Ioakimidis CS. Optimal operation of an energy management system for a grid-connected smart building considering photovoltaics' uncertainty and stochastic electric vehicles' driving schedule. Appl Energy 2018;210:1188-206.

[4] Wang Z, Wang L, Dounis AI, Yang R. Integration of plug-in hybrid electric vehicles into energy and comfort management for smart building. Energy Build 2012;47(47):260-6.

[5] Kuang Y, Chen Y, Hu M, Yang D. Influence analysis of driver behavior and building category on economic performance of electric vehicle to grid and building integration. Appl Energy 2017;207(1):427-37.

[6] Atia R, Yamada N. More accurate sizing of renewable energy sources under high levels of electric vehicle integration. Renew Energy 2015;81:918-25.

[7] Tao Y, Huang M, Yang L. Data-driven optimized layout of battery electric vehicle charging infrastructure. Energy 2018;150:735-44.

[8] StorHy (Hydrogen Storage Systems for Automotive Application). Pressure vessel. http://www.storhy.net/pages.php?page = E02.

[9] On board 700 bar Hydrogen Storage Type IV vessels: R\&D and manufacturing. http://www.storhy.net/train-in/PDF-TI/Poster/Poster_1.pdf.

[10] Hwang JJ. Review on development and demonstration of hydrogen fuel cell 
scooters. Renew Sustain Energy Rev 2012;16(6):3803-15.

[11] Zhang L, Xiang J. The performance of a grid-tied microgrid with hydrogen storage and a hydrogen fuel cell stack. Energy Convers Manag 2014;87:421-7.

[12] Cao S. Comparison of the energy and environmental impact by integrating a H 2 , vehicle and an electric vehicle into a zero-energy building. Energy Convers Manag 2016;123:153-73.

[13] Robledo CB, Oldenbroek V, Abbruzzese F, Wijk AJM. Integrating a hydrogen fuel cell electric vehicle with vehicle-to-grid technology, photovoltaic power and a residential building. Appl Energy 2018;215:615-29.

[14] Cao S, Alanne K. The techno-economic analysis of a hybrid zero-emission building system integrated with a commercial-scale zero-emission hydrogen vehicle. Appl Energy 2018;211:639-61.

[15] Hussain QE, Brigham DR, Maranville CW. Thermoelectric exhaust heat recovery for hybrid vehicles. Sae International Journal of Engines 2009;2(1):1132-42.

[16] Duparchy A, Leduc P, Bourhis G, Ternel C. Heat recovery for next generation of hybrid vehicles: simulation and design of a Rankine cycle system, 3. World Electric Vehicle2009; 3(3):440-456.

[17] Park S, Matsumoto T, Oda N. Numerical analysis of turbocharger response delay mechanism. SAE paper no. 2010-01-1226, presented at SAE 2010 world congress and exhibition, April 2010, Detroit, MI, USA, session: engine boosting systems (Part 1 of 2).

[18] Reynders G, Lopes RA, Marszal-Pomianowska A, Aelenei D, Martins J, Saelens D. Energy Flexible Buildings: an evaluation of definitions and quantification methodologies applied to thermal storage. Energy Build 2018;166:372-90.

[19] Jensen S $\emptyset$, Marszal-Pomianowska A, Lollini R, Pasut W, Knotzer A, Engelmann P, Stafford A, Reynders G. IEA EBC annex 67 energy flexible buildings. Energy Build 2017; 155:25-34.

[20] Smart Readiness Indicator. http://www.smarten.eu/wp-content/uploads/2018/ 05/20180502_Final-smartEn-contribution-SRI.pdf.

[21] Cao S, Klein K, Herkel S, Sirén K. Approaches to enhance the energy performance of a zero-energy building integrated with a commercial-scale hydrogen fueled zero-energy vehicle under Finnish and German conditions. Energy Convers Manag 2017;142:153-75.

[22] Aelenei D, Lopes RA, Aelenei L, Gonçalves H. Investigating the potential for energy flexibility in an office building with a vertical BIPV and a PV roof system. Renew Energy 2019;137:189-97.

[23] Sehar F, Pipattanasomporn M, Rahman S. Demand management to mitigate impacts of plug-in electric vehicle fast charge in buildings with renewables. Energy 2016;120:642-51.

[24] Ioakimidis CS, Thomas D, Rycerski P, Genikomsakis KN. Peak shaving and valley filling of power consumption profile in non-residential buildings using an electric vehicle parking lot. Energy 2018;148:148-58.

[25] Figure 2 is partially reprinted and partially redrawn from, Energy 148 Mirakhorli A, Dong B, Ioakimidis CS, Thomas D, Rycerski P, Genikomsakis KN. Peak shaving and valley filling of power consumption profile in non-residential buildings using an electric vehicle parking lot Copyright 2018;148-58. with permission from Elsevier.

[26] Amirioun MH, Kazemi A. A new model based on optimal scheduling of combined energy exchange modes for aggregation of electric vehicles in a residential complex. Energy 2014;69(5):186-98.

[27] Munkhammar J, Grahn P, Widén J. Quantifying self-consumption of on-site photovoltaic power generation in households with electric vehicle home charging. Sol Energy 2013;97(5):208-16.

[28] Karan E, Mohammadpour A, Asadi S. Integrating building and transportation energy use to design a comprehensive greenhouse gas mitigation strategy. Appl Energy 2016;165:234-43.

[29] Fernández RÁ. A more realistic approach to electric vehicle contribution to greenhouse gas emissions in the city. J Clean Prod 2018;172:949-59.

[30] Hoehne CG, Chester MV. Optimizing plug-in electric vehicle and vehicle-to-grid charge scheduling to minimize carbon emissions. Energy 2016;115:646-57.

[31] Flores RJ, Shaffer BP, Brouwer J. Electricity costs for a Level 3 electric vehicle fueling station integrated with a building. Appl Energy 2017;191:367-84.

[32] Zhang Y, Wang R, Zhang T, Liu Y, Guo B. Model predictive control-based operation management for a residential microgrid with considering forecast uncertainties and demand response strategies. IET Gener, Transm Distrib 2016;10(10):2367-78.

[33] Nunes P, Brito MC. Displacing natural gas with electric vehicles for grid stabilization. Energy 2017;141:87-96.

[34] Colmenar-Santos A, Linares-Mena AR, Borge-Diez D, Quinto-Alemany CD. Impact assessment of electric vehicles on islands grids: a case study for Tenerife (Spain). Energy 2017;120:385-96.

[35] Jin X, Mu Y, Jia H, Wu J, Xu X, Yu X, Qi F. Hierarchical management for building microgrid considering virtual storage system and plug-in electric vehicles. Energy Procedia 2016;103:219-24.

[36] Rahbari O, Vafaeipour M, Omar N, Rosen MA, Hegazy O, Timmermans JM, Heibati S, Bossche PVD. An optimal versatile control approach for plug-in electric vehicles to integrate renewable energy sources and smart grids. Energy 2017;134:1053-67.

[37] Umetani S, Fukushima Y, Morita H. A linear programming based heuristic algorithm for charge and discharge scheduling of electric vehicles in a building energy management system. Omega 2017;67:115-22.

[38] Fathabadi H. Novel solar powered electric vehicle charging station with the capability of vehicle-to-grid. Sol Energy 2017;142:136-43.

[39] Nsaliwa D, Vale R, Isaacs N. Housing and transportation: towards a multi-scale net zero emission housing approach for residential buildings in New Zealand. Energy Procedia 2015;75:2826-32.

[40] Cao S, Alanne K. Technical feasibility of a hybrid on-site $\mathrm{H}_{2}$ and renewable energy system for a zero-energy building with a $\mathrm{H}_{2}$ vehicle. Appl Energy
2015;158:568-83.

[41] Kam MVD, Sark WV. Smart charging of electric vehicles with photovoltaic power and vehicle-to-grid technology in a microgrid; a case study. Appl Energy 2015;152:20-30.

[42] Karan E, Asadi S, Ntaimo L. A stochastic optimization approach to reduce greenhouse gas emissions from buildings and transportation. Energy 2016;106:367-77.

[43] Islam MS. A techno-economic feasibility analysis of hybrid renewable energy supply options for a grid-connected large office building in southeastern section of France. Sustainable Cities and Society 2018;38:492-508.

[44] Wang S, Tang R. Supply-based feedback control strategy of air-conditioning systems for direct load control of buildings responding to urgent requests of smart grids. Appl Energy 2017;201:419-32.

[45] Lawrence TM, Boudreau MC, Helsen L, Henze G, Mohammadpour J, Noonan D, Patteeuw D, Pless S, Watson RT. Ten questions concerning integrating smart buildings into the smart grid. Build Environ 2016;108(11):273-83.

[46] Syed F, Fowler M, Wan D, Maniyali Y. An energy demand model for a fleet of plug in fuel cell vehicles and commercial building interfaced with a clean energy hub. Int J Hydrogen Energy 2010;35(10):5154-63.

[47] Bulut MB, Odlare M, Stigson P, Wallin F, Vassileva I. Active buildings in smart grids-exploring the views of the Swedish energy and buildings sectors. Energy Build 2016;117:185-98.

[48] Fathabadi H. Novel wind powered electric vehicle charging station with vehicle-togrid (V2G) connection capability. Energy Convers Manag 2017;136:229-39.

[49] Alirezaei M, Noori M, Tatari O. Getting to net zero energy building: investigating the role of vehicle to home technology. Energy Build 2016;130:465-76.

[50] Li X, Ogden J, Yang C. Analysis of the design and economics of molten carbonate fuel cell tri-generation systems providing heat and power for commercial buildings and $\mathrm{H}_{2}$ for FC vehicles. J Power Sources 2013;241(11):668-79.

[51] Alanne K, Cao S. Zero-energy hydrogen economy (ZEH2E) for buildings and communities including personal mobility. Renew Sustain Energy Rev 2017;71:697-711.

[52] Cao S, Hasan A, Sirén K. On-site energy matching indices for buildings with energy conversion, storage and hybrid grid connections. Energy Build 2013;64(1):423-38.

[53] Fathabadi H. Utilizing solar and wind energy in plug-in hybrid electric vehicles. Energy Convers Manag 2018;156:317-28.

[54] Fang Y, Asche F, Novan K. The costs of charging Plug-in Electric Vehicles (PEVs): within day variation in emissions and electricity prices. Energy Econ 2018;69:196-203.

[55] Widén J, Wäckelgård E, Lund PD. Options for improving the load matching capability of distributed photovoltaics: methodology and application to high-latitude data. Sol Energy 2009;83(11):1953-66.

[56] Johnston D. Solar energy systems installed on Chinese-style buildings. Energy Build 2007;39(4):385-92.

[57] Voss K, Sartori I, Napolitano A, Geier S, Gonzalves H, Hall M, Heiselberg P, Widén J, Candanedo JA, Musall E, Karlsson B, Torcellini P. Load matching and grid interaction of net zero energy buildings//Eurosun 2010. 2012. Graz, Austria, September 28 - October.

[58] Calise F, Cappiello FL, Carteni A, Accadia MD, Vicidomini M. A novel paradigm for a sustainable mobility based on electric vehicles, photovoltaic panels and electrical energy storage systems: case studies for Naples and Salerno (Italy). Renew Sustain Energy Rev 2019;111:97-114.

[59] Verbruggen B, Coninck RD, Baetens R, Saelens D, Helsen L, Driesen J. Grid impact indicators for active building simulation//Innovative Smart Grid Technologies. IEEE 2011:1-6.

[60] Munkhammar J, Grahn P, Widén J. Quantifying self-consumption of on-site photovoltaic power generation in households with electric vehicle home charging. Sol Energy 2013;97(5):208-16.

[61] DIRECTIVE 2012/27/EU OF THE EUROPEAN PARLIAMENT AND OF THE COUNCIL. https://eur-lex.europa.eu/legal-content/EN/TXT/?uri = celex \%3A32012L0027.

[62] Cao S, Hasan A, Sirén K. Matching analysis for on-site hybrid renewable energy systems of office buildings with extended indices. Appl Energy 2014;113(6):230-47.

[63] Cao S, Klein K, Herkel S, Sirén K. Approaches to enhance the energy performance of a zero-energy building integrated with a commercial-scale hydrogen fueled zero-energy vehicle under Finnish and German conditions. Energy Convers Manag 2017;142:153-75.

[64] Toyota Motor Sales, U.S.A.. Inc. Toyota FCHV fact sheet. http://pressroom.toyota. com/articledisplay.cfm?articleid = 2388; September 2008

[65] Toyota Motor Corporation. Powering the future Hydrogen fuel cell vehicles can change mobility forever. http://www.toyota-global.com/innovation/ environmentaltechnology/fuelcellvehicle/.

[66] Hyundai Motor Company. 2017 Tucson fuel cell, a hydrogen fuel cell car. Hyundai USA. https://www.hyundaiusa.com/tucsonfuelcell/index.aspx; 2017.

[67] American Honda Motor Co., Inc. 2017 clarity fuel cell - environmentally-conscious vehicles. American Honda Motor Co., Inc.; 2017http://automobiles.honda. com/ clarity\#technology.

[68] Toyota brings back the solar panel on the Plug-In Prius Prime - but now it powers the car [available]. https://electrek.co/2016/06/20/toyota-prius-plug-primesolar-panel/.

[69] Jarunglumlert T, Prommuak C, Putmai N, Pavasant P. Scaling-up bio-hydrogen production from food waste: feasibilities and challenges. Int J Hydrogen Energy 2017;43(2):634-48.

[70] Zhang Z, Li Y, Zhang H, He C, Zhang Q. Potential use and the energy conversion efficiency analysis of fermentation effluents from photo and dark fermentative biohydrogen production. Bioresour Technol 2017;245:884-9. 
[71] Oldenbroek V, Verhoef LA, Wijk AJMV. Fuel cell electric vehicle as a power plant: fully renewable integrated transport and energy system design and analysis for smart city areas. Int J Hydrogen Energy 2017;42(12):8166-96.

[72] Tariff Italy. Italy tariffs. https://www.pv-tech.org/tariffs/italy; 2013.

[73] FiT Germany. Feed-in tariffs in Germany. https://en.wikipedia.org/wiki/Feed- in tariffs in Germany\#cite note-1; 2014.

[74] Kolokotsa D. The role of smart grids in the building sector. Energy Build 2016;116:703-8.

[75] Shaukat N, Khan B, Ali SM, Mehmood CA, Khan J, Farid U, Majid M, Anwar SM, Jawad M, Ullah Z. A survey on electric vehicle transportation within smart grid system. Renew Sustain Energy Rev 2018;81:1329-49.

[76] Chakrabarti A, Proeglhoef R, Turu GB, Lambert R, Mariaud A, Acha S, et al. Optimisation and analysis of system integration between electric vehicles and UK decentralised energy schemes. Energy 2019;176:805-15.

[77] Mehrjerdi H, Bornapour M, Hemmati R, Ghiasi SMS. Unified energy management and load control in building equipped with wind-solar-battery incorporating electric and hydrogen vehicles under both connected to the grid and islanding modes. Energy 2019;168:919-30.

[78] Honold J, Kandler C, Wimmer P, Schropp B, Reichle R, Gröne M, Bünemann M, Klein J, Kufner M. Distributed integrated energy management systems in residential buildings. Appl Therm Eng 2016;114:1468-75.

[79] Mesarić P, Krajcar S. Home demand side management integrated with electric vehicles and renewable energy sources. Energy Build 2015;108:1-9.

[80] Dréau JL, Heiselberg P. Energy flexibility of residential buildings using short term heat storage in the thermal mass. Energy 2016;111:991-1002.

[81] Wang Y, Wang B, Chu CC, Pota H, Gadh R. Energy management for a commercial building microgrid with stationary and mobile battery storage. Energy Build 2016;116:141-50.

[82] Wu X, Hu X, Yin X, Zhang C, Qian S. Optimal battery sizing of a smart home via convex programming. Energy 2017;140:444-53.

[83] Lazzeroni P, Olivero S, Repetto M, Stirano F, Vallet M. Optimal battery management for vehicle-to-home and vehicle-to-grid operations in a residential case study. Energy 2019;175:704-21.

[84] Louis JN, Pongrácz E. Life cycle impact assessment of home energy management systems (HEMS) using dynamic emissions factors for electricity in Finland. Environ Impact Assess Rev 2017;67:109-16.

[85] Aziz M, Oda T, Kashiwagi T. Extended utilization of electric vehicles and their Reused batteries to support the building energy management system 2 . Energy Procedia 2015;75:1938-43.

[86] Jin X, Wu J, Mu Y, Wang M, Xu X, Jia H. Hierarchical microgrid energy management in an office building. Appl Energy 2017;208:480-94.

[87] Salpakari J, Rasku T, Lindgren J, Lund PD. Flexibility of electric vehicles and space heating in net zero energy houses: an optimal control model with thermal dynamics and battery degradation. Appl Energy 2017;190:800-12.

[88] Wu X, Hu X, Teng Y, Qian S, Cheng R. Optimal integration of a hybrid solar-battery power source into smart home nanogrid with plug-in electric vehicle. J Power Sources 2017;363:277-83.

[89] Wu X, Hu X, Moura S, Yin X, Pickert V. Stochastic control of smart home energy management with plug-in electric vehicle battery energy storage and photovoltaic array. J Power Sources 2016;333:203-12.

[90] Fanti MP, Mangini AM, Roccotelli M, Ukovich W. District microgrid management integrated with renewable energy sources, energy storage systems and electric vehicles. IFAC-PapersOnLine 2017;50(1):10015-20.

[91] Mirakhorli A, Dong B. Market and behavior driven predictive energy management for residential buildings. Sustainable Cities and Society 2018;38:723-35.

[92] Figure 4 is reprinted from Sustainable Cities and Society, 38 Mirakhorli A, Dong B. Market and behavior driven predictive energy management for residential buildings. Sustainable Cities and Society 2018;723-35:Copyright. with permission from Elsevier.

[93] Ehyaei MA, Ahmadi P, Atabi F, Heibati MR, Khorshidvand M. Feasibility study of applying internal combustion engines in residential buildings by exergy, economic and environmental analysis. Energy Build 2012;55(2):405-13.

[94] Figure 5 is partially reprinted and partially redrawn from Energy and Buildings, 55 Ehyaei MA, Ahmadi P, Atabi F, Heibati MR, Khorshidvand M. Feasibility study of applying internal combustion engines in residential buildings by exergy, economic and environmental analysis Copyright 2012;405-13. with permission from Elsevier.

[95] Recoverable heat for hot water. https://understandingchp.com/waste-heat/forhot-water-applications/.

[96] Diesel engine and gas turbine application. http://www.aqylon.com/applications/ energy-efficiency/whr-internal-combustion-engines/.

[97] Absorption cooling. https://www.cibse.org/getmedia/5c9a9e15-5103-4b70-8aa1 1b7456fdf9a5/Datasheet-7-Absorption-Cooling.pdf.aspx.

[98] Borri E, Tafone A, Comodi G, Romagnoli A. Improving liquefaction process of microgrid scale Liquid Air Energy Storage (LAES) through waste heat recovery (WHR) and absorption chiller. Energy Procedia 2017;143:699-704.

[99] Crane DT, Jackson GS. Optimization of cross flow heat exchangers for thermoelectric waste heat recovery. Energy Convers Manag 2004;45(9):1565-82.

[100] Hatazawa M, Sugita H, Ogawa T, Seo Y. Performance of a thermoacoustic sound wave generator driven with waste heat of automobile gasoline engine. Transactions of the Japan Society of Mechanical Engineers 2004;70(689):292-9.

[101] Conklin JC, Szybist JP. A highly efficient six-stroke internal combustion engine cycle with water injection for in-cylinder exhaust heat recovery. Energy 2010;35:1658-64.

[102] Dolz V, Novella R, García A, Sánchez J. HD Diesel engine equipped with a bottoming Rankine cycle as a waste heat recovery system. Part 1: study and analysis of the waste heat energy. Appl Therm Eng 2012;36(1):269-78.

[103] Wang T, Zhang Y, Zhang J, Shu G, Peng Z. Analysis of recoverable exhaust energy from a light-duty gasoline engine. Appl Therm Eng 2013;53(2):414-9.

[104] Table 4 is reprinted from Applied Thermal Engineering, 36 Dolz V, Novella R, García A, Sánchez J. HD Diesel engine equipped with a bottoming Rankine cycle as a waste heat recovery system. Part 1: study and analysis of the waste heat energy/ Table 4 Copyright 2012. p. 269-78. with permission from Elsevier.

[105] Shen L, Pu X, Sun Y, Chen J. A study on thermoelectric technology application in net zero energy buildings. Energy 2016;113:9-24.

[106] Liu ZB, Zhang L, Gong GC, Li HX, Tang GF. Review of solar thermoelectric cooling technologies for use in zero energy buildings. Energy Build 2015;102:207-16.

[107] Barone G, Buonomano A, Calise F, Forzano C, Palombo A. Building to vehicle to building concept toward a novel zero energy paradigm: modelling and case studies. Renew Sustain Energy Rev 2019;101:625-48.

[108] Pearre NS, Ribberink H. Review of research on V2X technologies, strategies, and operations. Renew Sustain Energy Rev 2019;105:61-70.

[109] Zhang X, Chau KT. An automotive thermoelectric-photovoltaic hybrid energy system using maximum power point tracking. Energy Convers Manag 2011;52(1):641-7.

[110] Fairbanks J. THERMOELECTRIC APPLICATIONS IN VEHICLES STATUS 2008. Us Desectionment of Energy; 2008http://ect2008.icmpe.cnrs.fr/Contributions/0-PL00-Fairbanks.pdf.

[111] Zhang X, Chau KT. An automotive thermoelectric-photovoltaic hybrid energy system using maximum power point tracking. Energy Convers Manag 2011;52(1):641-7.

[112] Yang J. Potential applications of thermoelectric waste heat recovery in the automotive industry. International Conference on Thermoelectrics. IEEE 2005:170-4.

[113] Saidur R, Rezaei M, Muzammil WK, Hassan MH, Paria S, Hasanuzzaman M. Technologies to recover exhaust heat from internal combustion engines. Renew Sustain Energy Rev 2012;16(8):5649-59.

[114] Stobart RK, Wijewardane A, Allen C. The potential for thermo-electric devices in passenger vehicle applications. SAE Technical Papers 2010. https://doi.org/10. 4271/2010-01-0833https://www.sae.org/publications/technical-papers/content/ 2010-01-0833/.

[115] Leong KY, Saidur R, Kazi SN, Mamun AH. Performance investigation of an automotive car radiator operated with nanofluid-based coolants (nanofluid as a coolant in a radiator). Appl Therm Eng 2010;30(17):2685-92.

[116] Rosen MA, Dincer I, Kanoglu M. Role of exergy in increasing efficiency and sustainability and reducing environmental impact. Energy Policy 2008;36(1):128-37.

[117] Chang WR, Hwang JJ, Wu W. Environmental impact and sustainability study on biofuels for transportation applications. Renew Sustain Energy Rev 2017;67:277-88.

[118] Chen XP, Hewitt N, Li ZT, Wu QM, Yuan X, Roskilly T. Dynamic programming for optimal operation of a biofuel micro CHP-HES system. Appl Energy 2017;208:132-41.

[119] Oro MV, Oliveira RG, Bazzo E. An integrated solution for waste heat recovery from fuel cells applied to adsorption systems. Appl Therm Eng 2018;136:747-54.

[120] Figure 7 is partially reprinted and partially redrawn from Applied Thermal Engineering, 136 Oro MV, Oliveira RG, Bazzo E. An integrated solution for waste heat recovery from fuel cells applied to adsorption systems Copyright 2018;747-54. with permission from Elsevier.

[121] Hasani M, Rahbar N. Application of thermoelectric cooler as a power generator in waste heat recovery from a PEM fuel cell - an experimental study. Int J Hydrogen Energy 2015;40(43):15040-51.

[122] Zhang H, Kong W, Dong F, Xu H, Chen B, Ni M. Application of cascading thermoelectric generator and cooler for waste heat recovery from solid oxide fuel cells. Energy Convers Manag 2017;148:1382-90.

[123] LCQ14. Electric vehicles. http://www.info.gov.hk/gia/general/201311/27/ P201311270370.htm.

[124] Hong Kong. A beacon city for EVs. https://electrek.co/2018/02/28/hong-kongelectric-cars-incentives-tesla/.

[125] Electric car buyers get new HK\$250,000 tax break but will it boost Hong Kong's flailing market? http://www.scmp.com/news/hong-kong/economy/article/ 2135066/electric-car-buyers-get-new-hk250000-tax-break-will-it-boost.

[126] LCQ2. Public charging facilities for electric vehicles. http://www.info.gov.hk/gia/ general/201712/13/P2017121300503.htm.

[127] Ashique RH, Salam Z, Aziz MJBA, Bhatti AR. Integrated photovoltaic-grid dc fast charging system for electric vehicle: a review of the architecture and control Renew Sustain Energy Rev 2016;69:1243-57.

[128] Ferro G, Laureri F, Minciardi R, Robba M. An optimization model for electrical vehicles scheduling in a smart grid. Sustainable Energy, Grids and Networks 2018;14:62-70.

[129] He J, Yang H, Tang TQ, Huang HJ. An optimal charging station location mode with the consideration of electric vehicle's driving range. Transp Res C Emerg Technol 2018;86:641-54.

[130] Teixeira ACR, Sodré JR. Simulation of the impacts on carbon dioxide emissions from replacement of a conventional Brazilian taxi fleet by electric vehicles. Energy 2016;115(3):1617-22.

[131] Electrofuels via direct electron transfer from electrodes to microbes. https://web. archive.org/web/20131010052121/http://arpa-e.energy.gov/?q = arpa-eprojects\%2Fbiofuels-solar-energy-and-bacteria-0.

[132] Liu Z, Chen Y, Zhuo R, Jia H. Energy storage capacity optimization for autonomy microgrid considering CHP and EV scheduling. Appl Energy 2018;210:1113-25.

[133] Ribberink H, Entchev E. Exploring the potential synergy between micro-cogeneration and electric vehicle charging. Appl Therm Eng 2014;71(2):677-85.

[134] Bhatia SK, Kim SH, Yoon JJ, Yang YH. Current status and strategies for second 
generation biofuel production using microbial systems. Energy Convers Manag 2017; 148:1142-56.

[135] Zhou B, Littler T, Foley A. Electric vehicle capacity forecasting model with application to load levelling. Power and Energy Society General Meeting. IEEE; 2017. p. $1-5$.

[136] Powerwall. https://www.tesla.com/en_HK/powerwall.

[137] Feed-in tariff scheme and renewable energy certificate Available: https://www. clpgroup.com/en/Media-Resources/site/Current\%20Releases\%20Documents/ 20180423/20180423_Factsheet_FiT_RE\%20Cert_en.pdf.

[138] Liu M, Xiong M, Deng H, Liu Q, Wu J, Xia P. Mobile energy internet. http://cn. arxiv.org/abs/1802.01570; 2018.

[139] Neubauer J, Pesaran A. The ability of battery second use strategies to impact plugin electric vehicle prices and serve utility energy storage applications. J Power Sources 2011;196(23):10351-8.

[140] Lih WC, Yen JH, Shieh FH, Liao YM. Second use of retired lithium-ion battery packs from electric vehicles: technological challenges, cost analysis and optima business model. International symposium on computer, consumer and control. IEEE Computer Society; 2012. p. 381-4.

[141] Cusenza MA, Guarino F, Longo S, Mistretta M, Cellura M. Reuse of electric vehicle batteries in buildings: an integrated load match analysis and life cycle assessment approach. Energy Build 2019;186:339-54.

[142] 2018 NISSAN LEAF. https://www.nissanusa.com/vehicles/electric-cars/leaf.html.

[143] "Vehicle to home" electricity supply system. https://www.nissan-global.com/EN/ TECHNOLOGY/OVERVIEW/vehicle_to_home.html.

[144] The Toyota fuel cell system (TFCS) moves the Mirai. http://www.toyota-global. com/innovation/environmental_technology/fuelcell_vehicle/.

[145] Mercedes-Benz GLC F-Cell 2018 first ride. https://www.autocar.co.uk/car-news/ new-cars/mercedes-benz-glc-f-cell-2018-first-ride.

[146] 2017 Honda clarity fuel cell emergency response guide. https://www.h2tools.org/ sites/default/files/HondaClarityFuelCellERG.pdf.

[147] Shiraki H, Nakamura S, Ashina S, Honjo K. Estimating the hourly electricity profile of Japanese households - coupling of engineering and statistical methods. Energy 2016;114:478-91.

[148] Honda clarity burns hydrogen, not rubber, in New York Available http://www. thedrive.com/new-cars/9187/2018-honda-clarity-burns-hydrogen-not-rubber-innew-york; 2018.

[149] Nissan unveils world's first Solid-Oxide Fuel Cell vehicle. http://nissannews.com/ en-US/nissan/usa/channels/us-united-states-nissan/releases/nissan-unveilsworld-s-first-solid-oxide-fuel-cell-vehicle.

[150] Nissan's ethanol-powered fuel cell vehicle. https://www.adandp.media/articles/ nissans-ethanol-powered-fuel-cell-vehicle.
[151] Le CN, Long NVD, Lee M. Novel heat-integrated and intensified biorefinery process for cellulosic ethanol production from lignocellulosic biomass. Energy Convers Manag 2017;141:367-77.

[152] Third and fourth generation biofuels: technologies, markets and economics through 2015. https://www.greentechmedia.com/research/report/third-andfourth-generation-biofuels\#gs.Kk2P3 U.

[153] Naik SN, Goud VV, Rout PK, Dalai AK. Production of first and second generation biofuels: a comprehensive review. Renew Sustain Energy Rev 2010;14(2):578-97.

[154] Aro EM. From first generation biofuels to advanced solar biofuels. Ambio 2016;45(1):24-31.

[155] Talom HL, Beyene A. Heat recovery from automotive engine. Appl Therm Eng 2009;29(2-3):439-44

[156] Lan S, Yang Z, Chen R, Stobart R. A dynamic model for thermoelectric generator applied to vehicle waste heat recovery. Appl Energy 2018;210:327-38.

[157] Tian Z, Gan W, Zhang X, Gu B, Yang L. Investigation on an integrated thermal management system with battery cooling and motor waste heat recovery for electric vehicle. Appl Therm Eng 2018;136:16-27.

[158] Alanne K, Söderholm N, Sirén K, Beausoleil-Morrison I. Techno-economic assessment and optimization of Stirling engine micro-cogeneration systems in residential buildings. Energy Convers Manag 2010;51(12):2635-46.

[159] Ambika K. Power generation using pressure from road side, vehicles and piezoelectric pressure transducer and inventor. International Journal of Innovative Research and Development 2015;4(3):21-4.

[160] Islam M, Rahman SK, Jyoti J. Generation of electricity using road transport pressure. Int J Eng Sci Innov Technol 2013;2(3):520-5.

[161] Saidur R, Leong KY, Mohammad HA. A review on applications and challenges of nanofluids. Renew Sustain Energy Rev 2011;15(3):1646-68.

[162] Reece SY, Hamel JA, Sung K, Jarvi TD, Esswein AJ, Pijpers JJ, Nocera DG. Wireless solar water splitting using silicon-based semiconductors and earth-abundant catalysts. Science 2011;334(6056):645-8.

[163] Nevin KP, Woodard TL, Franks AE, Summers ZM, Lovley DR. Microbial electrosynthesis: feeding microbes electricity to convert carbon dioxide and water to multicarbon extracellular organic compounds. mBio 2010;1(2):542-6.

[164] Absorption chillers for CHP systems. https://www.energy.gov/sites/prod/files/ 2017/06/f35/CHP-Absorption\%20Chiller-compliant.pdf.

[165] Zhou Y, Cao S. Energy flexibility investigation of advanced grid-responsive energy control strategieswith the static battery and electric vehicles: A case study of a high-rise office buildingin Hong Kong. Energy Convers Manag 2019. In press.

[166] Zhou Y, Cao S. Investigation of the flexibility of a residential net-zero energy building (NZEB) integrated with an electric vehicle in Hong Kong. Energy Proc 2019;158:2567-79. 